\title{
Methods for simultaneously evaluating reserve and permeability of undersaturated coalbed methane reservoirs using production data during the dewatering stage
}

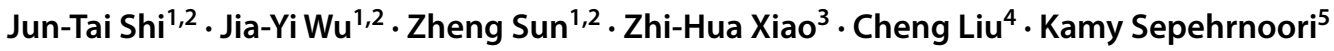

Received: 31 July 2019 / Published online: 9 January 2020

(c) The Author(s) 2020

\begin{abstract}
In this work, a flowing material balance equation (FMBE) is established for undersaturated coalbed methane (CBM) reservoirs, which considers immobile free gas expansion effect at the dewatering stage. Based on the established FMBE, five straight-line methods are proposed to determine the control area, initial water reserve, initial free gas reserve, initial adsorbed gas reserve, original gas in place, as well as permeability at the same time. Subsequently, the proposed FMBE methods for undersaturated CBM reservoirs are validated against a reservoir simulation software with and without considering free gas expansion. Finally, the proposed methods are applied in a field case when considering free gas expansion effect. Validation cases show that the straight-line relationships for the proposed five FMBE methods are excellent, and good agreements are obtained among the actual reserves and permeabilities and those evaluated by the proposed five FMBE methods, indicating the proposed five FMBE methods are effective and rational for CBM reservoirs. Results show that a small amount of free gas will result in a great deviation in reserve evaluation; hence, the immobile free gas expansion effect should be considered when establishing the material balance equation of undersaturated CBM reservoirs at the dewatering stage.
\end{abstract}

Keywords Coalbed methane $\cdot$ OGIP · Permeability evaluation $\cdot$ Flowing material balance equation $\cdot$ Gas expansion

\section{List of symbols}

$B_{\mathrm{g}} \quad$ Gas volume factor at current state $\left(\mathrm{sm}^{3} / \mathrm{m}^{3}\right)$

$B_{\mathrm{gi}} \quad$ Initial gas volume factor $\left(\mathrm{sm}^{3} / \mathrm{m}^{3}\right)$

$B_{\mathrm{w}} \quad$ Water volume factor at current state $\left(\mathrm{sm}^{3} / \mathrm{m}^{3}\right)$

$B_{\mathrm{wi}}$ Initial water volume factor $\left(\mathrm{sm}^{3} / \mathrm{m}^{3}\right)$

$b_{1} \quad y$-intercept of the straight line for Method $1\left[\left(\mathrm{~m}^{3} / \mathrm{d}\right) /\right.$ $\mathrm{MPa}]$

Edited by Yan-Hua Sun

Jun-Tai Shi

juntai.shi@gmail.com; shijuntai@cup.edu.cn

1 State Key Laboratory of Petroleum Resources and Prospecting, China University of Petroleum Beijing, No. 18, Fuxue Road, Changping District, Beijing 102249, China

2 MOE Key Laboratory of Petroleum Engineering, China University of Petroleum Beijing, No. 18, Fuxue Road, Changping District, Beijing 102249, China

3 PetroChina Coalbed Methane Company Limited, Beijing 100028, China

4 PetroChina Zhejiang Oil Field Company Limited, Hangzhou 310023, China

5 The University of Texas, Austin, TX 78712, USA $b_{2} \quad y$-intercept of the straight line for Method $2[\mathrm{MPa} /$ $\left.\left(\mathrm{m}^{3} / \mathrm{d}\right)\right]$

$b_{3} \quad y$-intercept of the straight line for Method $3[\mathrm{MPa} /$ $\mathrm{m}^{3}$ ]

$b_{4} \quad y$-intercept of the straight line for Method $4[\mathrm{MPa} /$ $\left.\left(\mathrm{m}^{3} / \mathrm{d}\right)\right]$

$b_{5} \quad y$-intercept of the straight line for Method $5[\mathrm{MPa} /$ $\left.\left(\mathrm{m}^{3} / \mathrm{d}\right)\right]$

$c_{\mathrm{g}} \quad$ Gas compressibility $\left(\mathrm{MPa}^{-1}\right)$

$\bar{c}_{\mathrm{g}} \quad$ Average gas compressibility $\left(\mathrm{MPa}^{-1}\right)$

$c_{\mathrm{p}} \quad$ Pore compressibility $\left(\mathrm{MPa}^{-1}\right)$

$c_{\mathrm{t}} \quad$ Total compressibility $\left(\mathrm{MPa}^{-1}\right)$

$c_{\mathrm{w}} \quad$ Water compressibility $\left(\mathrm{MPa}^{-1}\right)$

$G \quad$ Initial free gas reserve $\left(\mathrm{m}^{3}\right)$

$G_{\mathrm{p}} \quad$ Cumulative gas production $\left(\mathrm{m}^{3}\right)$

$G_{\mathrm{r}} \quad$ Residual gas reserve $\left(\mathrm{m}^{3}\right)$

$h \quad$ Reservoir thickness $(\mathrm{m})$

$k_{\mathrm{r}} \quad$ Relative permeability (fraction)

$k_{\mathrm{w}} \quad$ Permeability at current pressure $(\mathrm{mD})$

$m_{1} \quad$ Slope of the straight line for Method $1\left(\mathrm{~d}^{-1}\right)$

$m_{2} \quad$ Slope of the straight line for Method $2\left(\mathrm{MPa} / \mathrm{m}^{3}\right)$

$m_{3} \quad$ Slope of the straight line for Method $3\left[\mathrm{MPa} /\left(\mathrm{m}^{3} / \mathrm{d}\right)\right]$

$m_{4} \quad$ Slope of the straight line for Method $4\left[\mathrm{MPa} /\left(\mathrm{m}^{3} / \mathrm{d}\right)\right]$ 


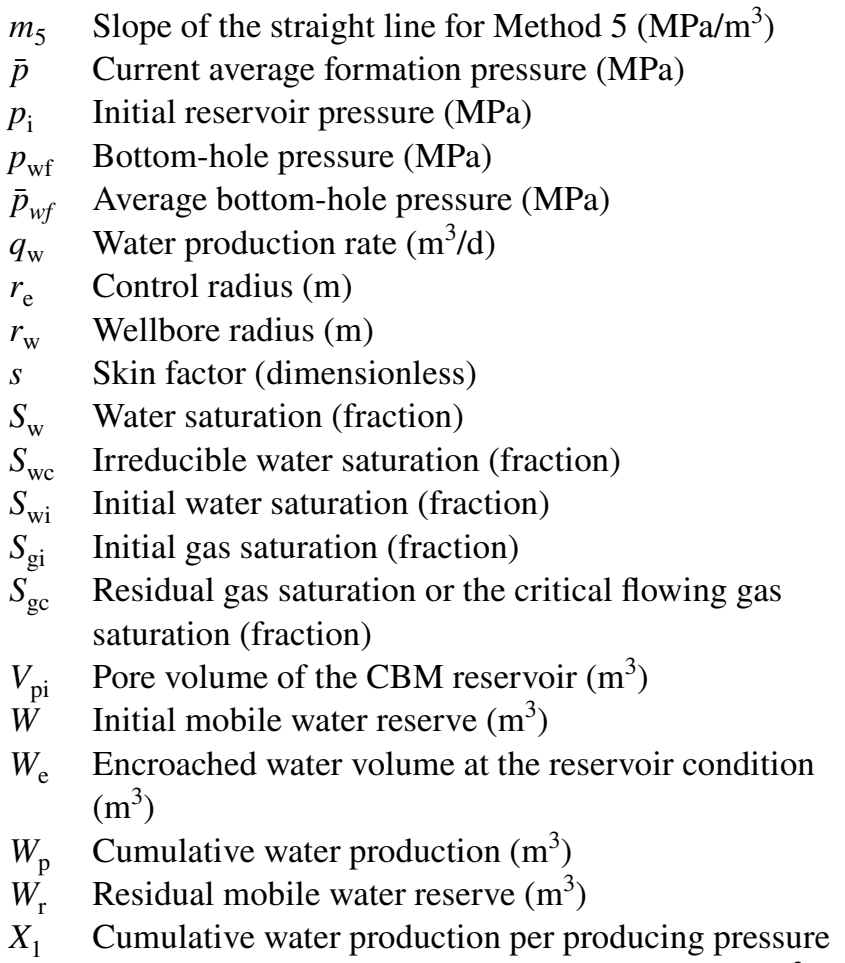

$X_{1}$ Cumulative water production per producing pressure
drop, which is the value of $x$ axis for Method $1\left(\mathrm{~m}^{3} /\right.$ $\mathrm{MPa}$ )

$X_{2} \quad$ Average producing time, which is the value of $x$ axis for Method 2 (d)

$X_{3} \quad$ Reciprocal of the average producing time, which is the value of $x$ axis for Method $3\left(\mathrm{~d}^{-1}\right)$

$X_{4} \quad$ Ratio of yesterday's water production rate to today's water production rate, which is the value of $x$ axis for Method 4 (dimensionless)

$X_{5} \quad$ Ratio of the average cumulative water production to the average water production rate, which is the value of $x$ axis for Method 5 (d)

$Y_{1} \quad$ Water productivity index, which is the value of $y$ axis for Method $1\left[\left(\mathrm{~m}^{3} / \mathrm{d}\right) / \mathrm{MPa}\right]$

$Y_{2}$ Reciprocal of water productivity index, which is the value of $y$ axis for Method $2\left[\mathrm{MPa} /\left(\mathrm{m}^{3} / \mathrm{d}\right)\right]$

$Y_{3} \quad$ Producing pressure drop per cumulative water production, which is the value of $y$ axis for Method 3 $\left(\mathrm{MPa} / \mathrm{m}^{3}\right)$

$Y_{4} \quad$ Ratio of bottom-hole pressure change from yesterday to today to the today's water production rate, which is the value of $y$ axis for Method $4\left[\mathrm{MPa} /\left(\mathrm{m}^{3} / \mathrm{d}\right)\right]$

$Y_{5}$ Ratio of the average producing pressure drop to the average water production rate, which is the value of $y$ axis for Method $5\left[\mathrm{MPa} /\left(\mathrm{m}^{3} / \mathrm{d}\right)\right]$

$\mu_{\mathrm{w}} \quad$ Dynamic viscosity of water (mPa s)

$\phi_{\mathrm{i}} \quad$ Initial porosity of coal formation (fraction)

\section{Introduction}

Coalbed methane (CBM) is a green, clean, and environmentally friendly natural resource which can make up the energy shortage (Clarkson 2013; Liu and Harpalani 2013; Adeboye and Bustin 2013). The CBM reservoir, as one of the unconventional gas reservoirs, has unique flow mechanism and production schedule (Aminian et al. 2004; Clarkson and Salmachi 2017; Jenkins and Boyer 2008). CBM is produced through dewatering to make adsorbed gas desorb from the interface of coal matrix after the critical desorption pressure is achieved (Jenkins and Boyer 2008; Sun et al. 2017, 2018a). Before gas production, only water can flow in the cleat system, even though in some cases there is a small amount of free gas; but since its saturation is less than the critical flowing saturation, gas cannot flow but will expand in volume.

Reserve evaluation is one of the important issues before and during the development of CBM reservoirs (Zhou and Guan 2016). The volumetric method is often applied to estimate the original gas in place (OGIP) of a CBM reservoir before its development (Saulsberry et al. 1996; Zahner 1997). Dynamic methods (King 1990, 1993; Clarkson et al. 2007; Ahmed et al. 2006; Salmachi and Karacan 2017) are usually used to evaluate and prove the previous calculated OGIP of a CBM reservoir by using production data during its development. Because the control area of the coal formation is not easy to determine, the OGIP evaluated by the volumetric method is a low probability value and often considered as a reference, while the dynamic methods which use the production performances of CBM wells are more credible (Guzman et al. 2014). However, most dynamic methods, such as the material balance equation (MBE) method, are limited in use because it is impossible to shut in all CBM wells to measure the average pressure (Morad and Clarkson 2008). Shi et al. (2018a) proposed a history matching method to generate the average pressure history with gas and water productions of the CBM wells, and then applied the proposed material balance equation for coalbed methane to estimate the OGIP on the basis of the generated average pressure history, the actual cumulative water and gas productions, as well as the CBM formation and fluid properties.

Permeability of the coal formation is a very important parameter for the effective production of CBM reservoirs (Clarkson et al. 2011; Yan et al. 2015; Sun et al. 2018b, 2018c). Currently, there are some methods for determining the permeability of the coal formation, such as core laboratory test (Gash 1991; Wang et al. 2011; Adeboye and Bustin 2013; Li et al. 2014), well logging (Li et al. 2011; Fu et al. 2009; Karacan 2009), well testing (Al-Khalifa et al. 1989; Conway et al. 1995; Salmachi et al. 2019), and production 
performance analysis (Clarkson et al. 2007; Yarmohammadtooski et al. 2017; Zhu et al. 2018). Core laboratory test is time consuming, expensive, and limited in sampling: sometimes for the coal formation with a complex cleat system under high stress condition, the coal cores used in laboratory deviate from the actual situations from downhole to surface, resulting in a larger deviation of the measured permeability from the actual value (Yan et al. 2015). Well logging is a very convenient method for determining the permeability of the coal formation, but the evaluated permeability is proven to be much lower than the actual value based on many field case studies. The reason is that the measured permeability by well logging is actually the permeability of the coal seam in the vicinity of the wellbore, basically within a small region with a radius of $1 \mathrm{~m}$, which has been damaged by well drilling and completion. Thus, the permeability evaluated by well logging cannot represent the whole CBM reservoir. Well testing method is a more concise method for evaluating the permeability of the coal formation (Conway et al. 1995; Fu et al. 2009): with some amount of water injected into the CBM wells and then these wells shut in for a while, the permeability of the coal formation can be determined by using the decreasing history of the bottom-hole pressure. Because the pressure propagated area is large after shut-in for a while, the permeability evaluated by this method is more credible. Otherwise, the well is shut in after a period of gas production without injecting water, and the bottom-hole pressure is measured and used to interpret the permeability of the coal formation (Salmachi et al. 2019). However, the well testing method needs to inject water into the well or to shut in the well for a period; it is time consuming and affects the production schedule; more importantly, it is impossible to shut in all wells to test the permeability; so other methods are needed to be proposed. Fortunately, production performance analysis method (Clarkson et al. 2007; Yarmohammadtooski et al. 2017; Zhu et al. 2018; Shi et al. 2018b, 2019a) can handle the aforementioned issues; it is not required to shut in the well and hence it does not affect the production schedule. The evaluated permeability is the average value within the control area of the CBM well, so it is more accurate and rational. Furthermore, only production performance data, such as the bottom-hole pressure history and water production history, are needed, which, however, are very easy to acquire. This method is simple, convenient, and should be broadly applied in CBM fields.

The reserve evaluation methods can only be used to estimate the OGIP, while the permeability evaluation methods can only be used to determine the permeability of the coal formation. There are two types of methods for evaluating both reserve and permeability simultaneously, which are the flowing material balance equation (FMBE) method and history matching in numerical simulation. The history matching method is complicated and time consuming, resulting in that its usage is limited in reality, while the FMBE method is a very good method for determining both reserve and permeability simultaneously using only the production performance data and the properties of the CBM formation and fluids.

FMBE for gas reservoirs suitable for boundary-dominated flow period was first proposed by Mattar and McNeil (1995). This method utilizes information obtained from production and bottom-hole flowing pressure to quantify the gas reserve, without having to shut-in the well. Hence, the FMBE has been widely used to determine the reservoir properties and reserves. Mattar et al. (2006), Ibrahim and Wattenbarger (2006), Clarkson (2008), Clarkson et al. (2007, 2008, 2012), Clarkson and Salmachi (2017), Gerami et al. (2007) and Sun et al. (2018d) modified the FMBE of CBM reservoirs considering the matrix shrinkage, stress sensitivity, gas desorption, gas-water two phase, and pressure-saturation relationship. Clarkson et al. (2007) and Clarkson (2008) proposed a new FMBE method considering complex CBM reservoir behavior, such as dynamic permeability and two-phase flow, which can be used to determine the water reserve, gas reserve and permeability of the coal formation by the way of straight-line fitting. However, this method is primarily limited to analyzing single-layer reservoirs. Clarkson (2008) extended their previous work; the new FMBE can be applied to CBM wells producing with multi-layers. Clarkson et al. (2012) developed the FMBE method to twophase (gas and water) CBM reservoirs producing from vertically fractured and horizontal wells. In the next endeavor, Clarkson and Salmachi (2017) amended both gas and water phase version of the FMBE, accounting for absolute permeability (stress-dependent and desorption-dependent) and gas/ water relative permeability change. It should be noted that the effects of absolute permeability and relative permeability were first time incorporated into rate-transient analysis in their research. However, the free gas expansion is not considered in their models, resulting in the prospect that the control area of the CBM well is often overestimated and even reaches an unrealistic value for some CBM wells. Thus, a more realistic FMBE method considering free gas expansion effect should be established.

In all, the reserve and permeability evaluations of the coal formation are very important for the development and effective production of CBM reservoirs. As one of the unconventional gas reservoirs, the unique flow mechanism and production schedule of CBM reservoirs make the evaluation of reserve and permeability complicated. Many methods have been proposed in the literature to estimate the reserve and permeability separately. Evaluating these two important parameters simultaneously is challenging. The FMBE may be one effective approach to satisfy this acquisition. Few studies have considered the immobile free gas expansion effect on the reserve and permeability evaluations. However, the free gas expansion may make contribution to water 
production of CBM wells at the dewatering stage; it is necessary to consider this effect during reserve and permeability evaluations.

In this work, the MBE of an undersaturated CBM reservoir at the dewatering stage is derived, in which the immobile free gas expansion is considered in the total compressibility expression. Then, coupling the water productivity equation of the CBM well and the MBE for undersaturated CBM reservoirs at the dewatering stage before gas production, the FMBE for an undersaturated CBM reservoir considering immobile free gas expansion effect is established. On the basis of the proposed FMBE, five straight-line methods are proposed to determine the control area, initial water reserve, initial free gas reserve, initial adsorbed gas reserve, OGIP, as well as permeability at the same time. Subsequently, the proposed FMBE methods for undersaturated CBM reservoirs are validated against the reservoir simulation software with and without considering free gas expansion. Finally, the proposed FMBE is applied in a field case considering the free gas expansion effect.

\section{Model establishment}

In this section, the MBE for an undersaturated CBM reservoir at the early dewatering stage, the water productivity equation of a CBM well, and the FMBE for an undersaturated CBM reservoir at the early dewatering stage are established.

\subsection{Assumptions}

The MBE, water productivity equation, and FMBE of an undersaturated $\mathrm{CBM}$ reservoir are developed on the basis of the following assumptions.

1. Although there is a small amount of free gas, only water phase can flow in coal formation because the gas saturation is lower than the critical flowing gas saturation.

2. The well bottom-hole pressure is higher than the critical desorption pressure, i.e., the adsorbed gas does not start to desorb.

3. Single water phase flow lasts for a long time and the pressure has propagated to the boundary or the middle of multiple CBM wells, i.e., the pseudo-steady state has been achieved.

4. Pore compressibility $c_{\mathrm{p}}$, water compressibility $c_{\mathrm{w}}$, initial water saturation $S_{\text {wi }}$, reservoir thickness $h$, and initial porosity $\varphi_{\mathrm{i}}$ are assumed to be acquired through core tests or well logs before data fitting.

\subsection{The MBE for an undersaturated CBM reservoir at the early dewatering stage}

For an undersaturated CBM reservoir with some small amount of free gas, in case that the initial reservoir pressure is much higher than the critical desorption pressure, and the actual gas saturation is lower than the residual gas saturation, i.e., critical flowing gas saturation, there will be a long period of dewatering stage before gas production. The material balance equation is applicable after the pseudo-steady state is achieved, i.e., the pressure should have propagated to the outer boundary. The material balance equation for a CBM reservoir after desorption is more complicated (Shi et al. 2018a), so in order to avoid the interferences of porosity change and water saturation change resulting from gas desorption on reserve and permeability evaluation, the material balance equation before gas desorption stage is analyzed in this study. During the establishment of the material balance equation, it is assumed that the pseudo-steady state should have been achieved and the bottom-hole pressure should be higher than the critical desorption pressure, i.e., gas desorption has not happened.

According to the material balance principle, the residual fluid reserve is equal to the difference between the initial fluid reserve and the cumulative fluid production.

$G_{\mathrm{r}}=G-G_{\mathrm{p}}$

$W_{\mathrm{r}}=W-W_{\mathrm{p}}$

The initial pore volume (which includes the pore volumes occupied by gas, mobile water, and immobile water at the initial reservoir conditions) is equal to the volumes occupied by residual gas, residual mobile water, and immobile water at the current reservoir conditions, plus the pore shrinkage volume owing to the pore compressibility and the encroached water volume. In addition, the pore volume occupied by the irreducible water at the current reservoir conditions is actually equal to the pore volume occupied by immobile water at the initial reservoir conditions plus the expansion volume of immobile water. Thus, the following equation can be derived $G B_{\mathrm{gi}}+W B_{\mathrm{wi}}+V_{\mathrm{pi}} S_{\mathrm{wc}}=G_{\mathrm{r}} B_{\mathrm{g}}+W_{\mathrm{r}} B_{\mathrm{w}}+V_{\mathrm{pi}} S_{\mathrm{wc}}+\Delta V_{\mathrm{p}}+\Delta V_{\mathrm{wc}}+W_{\mathrm{e}}$

where $\Delta V_{\mathrm{p}}$ and $\Delta V_{\mathrm{wc}}$ can be derived using the definitions of pore compressibility and water compressibility, which can be expressed as

$$
\begin{aligned}
\Delta V_{\mathrm{p}} & =V_{\mathrm{pi}} c_{\mathrm{p}}\left(p_{\mathrm{i}}-\bar{p}\right) \\
\Delta V_{\mathrm{wc}} & =V_{\mathrm{pi}} S_{\mathrm{wc}} c_{\mathrm{w}}\left(p_{\mathrm{i}}-\bar{p}\right)
\end{aligned}
$$


Substituting Eqs. (3) into (2) yields

$$
\begin{aligned}
G B_{\mathrm{gi}}+W B_{\mathrm{wi}}= & \left(G-G_{\mathrm{p}}\right) B_{\mathrm{g}}+\left(W-W_{p}\right) B_{\mathrm{w}} \\
& +V_{\mathrm{pi}} c_{\mathrm{p}}\left(p_{\mathrm{i}}-\bar{p}\right)+V_{\mathrm{pi}} S_{\mathrm{wc}} c_{\mathrm{w}}\left(p_{\mathrm{i}}-\bar{p}\right)+W_{\mathrm{e}} .
\end{aligned}
$$

Organizing Eq. (4) gives

$$
\begin{aligned}
G_{\mathrm{p}} B_{\mathrm{g}}+W_{\mathrm{p}} B_{\mathrm{w}}-W_{\mathrm{e}}= & G\left(B_{\mathrm{g}}-B_{\mathrm{gi}}\right)+W\left(B_{\mathrm{w}}-B_{\mathrm{wi}}\right) \\
& +V_{\mathrm{pi}}\left(c_{\mathrm{p}}+S_{\mathrm{wc}} c_{\mathrm{w}}\right)\left(p_{\mathrm{i}}-\bar{p}\right) .
\end{aligned}
$$

Because

$$
\begin{aligned}
& G=\frac{V_{\mathrm{pi}}\left(1-S_{\mathrm{wi}}\right)}{B_{\mathrm{gi}}} \\
& W=\frac{V_{\mathrm{pi}}\left(S_{\mathrm{wi}}-S_{\mathrm{wc}}\right)}{B_{\mathrm{wi}}} .
\end{aligned}
$$

Substituting Eqs. (6) and (7) into Eq. (5) yields

$$
\begin{aligned}
G_{\mathrm{p}} B_{\mathrm{g}}+W_{\mathrm{p}} B_{\mathrm{w}}-W_{\mathrm{e}}= & V_{\mathrm{pi}}\left(1-S_{\mathrm{wi}}\right) \frac{\left(B_{\mathrm{g}}-B_{\mathrm{gi}}\right)}{B_{\mathrm{gi}}} \\
& +V_{\mathrm{pi}}\left(S_{\mathrm{wi}}-S_{\mathrm{wc}}\right) \frac{\left(B_{\mathrm{w}}-B_{\mathrm{wi}}\right)}{B_{\mathrm{wi}}} \\
& +V_{\mathrm{pi}}\left(c_{\mathrm{p}}+S_{\mathrm{wc}} c_{\mathrm{w}}\right)\left(p_{\mathrm{i}}-\bar{p}\right)
\end{aligned}
$$

At the dewatering stage of undersaturated CBM reservoirs, before the gas production, $G_{\mathrm{p}}$ is zero; hence, Eq. (8) can be changed to

$$
\begin{aligned}
W_{\mathrm{p}} B_{\mathrm{w}}-W_{\mathrm{e}}= & V_{\mathrm{pi}}\left(1-S_{\mathrm{wi}}\right) \frac{\left(B_{\mathrm{g}}-B_{\mathrm{gi}}\right)}{B_{\mathrm{gi}}} \\
& +V_{\mathrm{pi}}\left(S_{\mathrm{wi}}-S_{\mathrm{wc}}\right) \frac{\left(B_{\mathrm{w}}-B_{\mathrm{wi}}\right)}{B_{\mathrm{wi}}} \\
& +V_{\mathrm{pi}}\left(c_{\mathrm{p}}+S_{\mathrm{wc}} c_{\mathrm{w}}\right)\left(p_{\mathrm{i}}-\bar{p}\right)
\end{aligned}
$$

According to the definitions of water compressibility and gas compressibility,

$c_{\mathrm{w}}=-\frac{\Delta B_{\mathrm{w}}}{B_{\mathrm{wi}} \Delta p}$

$c_{\mathrm{g}}=-\frac{\Delta\left[\left(G-G_{\mathrm{p}}\right) B_{\mathrm{g}}\right]}{G B_{\mathrm{gi}} \Delta p}$.

Because $G_{\mathrm{p}}$ is zero at the early dewatering stage,

$c_{\mathrm{g}}=-\frac{\Delta B_{\mathrm{g}}}{B_{\mathrm{gi}} \Delta p}$.

Thus, the following two equations can be obtained:
$\frac{B_{\mathrm{w}}-B_{\mathrm{wi}}}{B_{\mathrm{wi}}}=c_{\mathrm{w}}\left(p_{\mathrm{i}}-\bar{p}\right)$

$\frac{B_{\mathrm{g}}-B_{\mathrm{gi}}}{B_{\mathrm{gi}}}=\bar{c}_{\mathrm{g}}\left(p_{\mathrm{i}}-\bar{p}\right)$

where $\bar{c}_{\mathrm{g}}$ can be calculated using the $Z$ factor plot versus pressure, which can be expressed as $\bar{c}_{\mathrm{g}}=1 / \bar{p}-(1 / Z)(\partial Z / \partial \bar{p})$, in which the average pressure at the time range for data fitting can be simply calculated by $\bar{p}=\left(p_{\mathrm{i}}+\bar{p}_{\mathrm{wf}}\right) / 2$.

Substituting Eqs. (13) and (14) into Eq. (9) and organizing it gives

$W_{\mathrm{p}} B_{\mathrm{w}}-W_{\mathrm{e}}=V_{\mathrm{pi}}\left(p_{\mathrm{i}}-\bar{p}\right)\left[c_{\mathrm{p}}+S_{\mathrm{wi}} c_{\mathrm{w}}+\left(1-S_{\mathrm{wi}}\right) \bar{c}_{\mathrm{g}}\right]$

For homogeneous undersaturated CBM reservoirs, if no free gas exists, before the bottom-hole pressure decreases below the critical desorption pressure, single water phase flow exists. The water is produced owing only to the pore and water expansion. If there is a small amount of free gas at the initial state in undersaturated CBM reservoirs and the initial gas saturation is less than the critical flowing gas saturation, this small amount of gas will expand with the water production at the early dewatering stage. In this case, the total compressibility will increase dramatically because of gas expansion, even though the initial gas saturation is very small. The total compressibility can be expressed as

$c_{\mathrm{t}}=c_{\mathrm{p}}+S_{\mathrm{wi}} c_{\mathrm{w}}+\left(1-S_{\mathrm{wi}}\right) \bar{c}_{\mathrm{g}}$.

\subsection{The water productivity equation of a CBM well}

Based on the Darcy flow equation, the relationship between the water production and the pressure gradient can be expressed as

$q_{\mathrm{w}}=\frac{2 \pi r h k_{\mathrm{w}}}{\mu_{\mathrm{w}} B_{\mathrm{w}}} \frac{\mathrm{d} p}{\mathrm{~d} r}$.

Integrating Eq. (17) from the wellbore to the reservoir and converting SI units to field units yield

$\frac{0.543 k_{\mathrm{w}} h}{\mu_{\mathrm{w}} B_{\mathrm{w}} q_{\mathrm{w}}} \int_{p_{\mathrm{wf}}}^{\bar{p}} \mathrm{~d} p=\int_{r_{\mathrm{w}}}^{\bar{r}} \frac{1}{r} \mathrm{~d} r$.

Organizing Eq. (18) gives

$\frac{0.543 k_{\mathrm{w}} h\left(\bar{p}-p_{\mathrm{wf}}\right)}{\mu_{\mathrm{w}} B_{\mathrm{w}} q_{\mathrm{w}}}=\ln \frac{\bar{r}}{r_{\mathrm{w}}}$.

According to fluid flow principle in porous media and oil and gas reservoir engineering (Li 2008; Cheng 2011), one obtains 
$\bar{r}=0.472 r_{\mathrm{e}}$

Considering the well completion pattern and skin factor, $r_{\mathrm{w}}$ in Eq (19) is replaced by $r_{\mathrm{wc}}$. For a vertically fractured CBM well, $r_{\mathrm{wc}}=\left(L_{\mathrm{f}} / 2\right) \cdot \mathrm{e}^{-s}$ (Shi et al. 2018b, c; Dejam et al. 2014, 2017, 2018a, b; Dejam 2019; Zhang et al. 2018); for a damaged or stimulated vertical well, $r_{\mathrm{wc}}=r_{\mathrm{w}} \cdot \mathrm{e}^{-s}$. If a well is damaged, the skin factor $s$ will be a positive value, while if the well is stimulated, the skin factor $s$ will be a negative value.

Thus, Eq. (19) will be changed to

$\frac{0.543 k_{\mathrm{w}} h\left(\bar{p}-p_{\mathrm{wf}}\right)}{\mu_{\mathrm{w}} B_{\mathrm{w}} q_{\mathrm{w}}}=\ln \frac{0.472 r_{\mathrm{e}}}{r_{\mathrm{wc}}}$.

\subsection{The FMBE for an undersaturated CBM reservoir at the early dewatering stage}

The FMBE of CBM reservoirs can be derived by coupling the $\mathrm{MBE}$ of $\mathrm{CBM}$ reservoirs with the productivity equation of a CBM well.

The water productivity equation of a CBM well Eq. (21) can be rewritten into the following form:

$\left(\bar{p}-p_{\mathrm{i}}\right)+\left(p_{\mathrm{i}}-p_{\mathrm{wf}}\right)=\frac{\mu_{\mathrm{w}} B_{\mathrm{w}} q_{\mathrm{w}}}{0.543 k_{\mathrm{w}} h} \ln \frac{0.472 r_{\mathrm{e}}}{r_{\mathrm{wc}}}$.

Substituting Eqs. (15) into (22) yields

$\left(p_{\mathrm{i}}-p_{\mathrm{wf}}\right)-\frac{W_{\mathrm{p}} B_{\mathrm{w}}-W_{\mathrm{e}}}{V_{\mathrm{pi}}\left[c_{\mathrm{p}}+S_{\mathrm{wi}} c_{\mathrm{w}}+\left(1-S_{\mathrm{wi}}\right) \bar{c}_{\mathrm{g}}\right]}=\frac{\mu_{\mathrm{w}} B_{\mathrm{w}} q_{\mathrm{w}}}{0.543 k_{\mathrm{w}} h} \ln \frac{0.472 r_{\mathrm{e}}}{r_{\mathrm{wc}}}$.

If encroached water is not considered, i.e., $W_{\mathrm{e}}$ is equal to 0, Eq. (23) can be written as:

$\left(p_{\mathrm{i}}-p_{\mathrm{wf}}\right)-\frac{W_{\mathrm{p}} B_{\mathrm{w}}}{V_{\mathrm{pi}}\left[c_{\mathrm{p}}+S_{\mathrm{wi}} c_{\mathrm{w}}+\left(1-S_{\mathrm{wi}}\right) \bar{c}_{\mathrm{g}}\right]}=\frac{\mu_{\mathrm{w}} B_{\mathrm{w}} q_{\mathrm{w}}}{0.543 k_{\mathrm{w}} h} \ln \frac{0.472 r_{\mathrm{e}}}{r_{\mathrm{wc}}}$.

Equations (23) and (24) will be the FMBEs for an undersaturated CBM reservoir at the early dewatering stage considering the immobile free gas expansion effect.

\section{Five methods for evaluating reserve and permeability of undersaturated CBM reservoirs}

In this section, five methods for evaluating reserve and permeability of undersaturated CBM reservoirs, considering free gas expansion, are developed on the basis of the proposed FMBE for an undersaturated CBM reservoir at the early dewatering stage.

\subsection{Method 1}

Organizing Eq. (24) yields

$$
\begin{gathered}
\frac{0.543 k_{\mathrm{w}} h}{\mu_{\mathrm{w}} B_{\mathrm{w}} \ln \frac{0.472 r_{\mathrm{e}}}{r_{\mathrm{wc}}}}\left(p_{\mathrm{i}}-p_{\mathrm{wf}}\right)-\frac{0.543 k_{\mathrm{w}} h}{\mu_{\mathrm{w}} B_{\mathrm{w}} \ln \frac{0.472 r_{\mathrm{e}}}{r_{\mathrm{wc}}}} \\
\frac{W_{\mathrm{p}} B_{\mathrm{w}}}{V_{\mathrm{pi}}\left[c_{\mathrm{p}}+S_{\mathrm{wi}} c_{\mathrm{w}}+\left(1-S_{\mathrm{wi}}\right) \bar{c}_{\mathrm{g}}\right]}=q_{\mathrm{w}} .
\end{gathered}
$$

Finally, the following equation is derived:

$$
\begin{aligned}
\frac{q_{\mathrm{w}}}{p_{\mathrm{i}}-p_{\mathrm{wf}}}= & \frac{0.543 k_{\mathrm{w}} h}{\mu_{\mathrm{w}} B_{\mathrm{w}} \ln \frac{0.472 r_{\mathrm{e}}}{r_{\mathrm{wc}}}}-\frac{0.543 k_{\mathrm{w}} h}{\mu_{\mathrm{w}} B_{\mathrm{w}} \ln \frac{0.472 r_{\mathrm{e}}}{r_{\mathrm{wc}}}} . \\
& \frac{B_{\mathrm{w}}}{V_{\mathrm{pi}}\left[c_{\mathrm{p}}+S_{\mathrm{wi}} c_{\mathrm{w}}+\left(1-S_{\mathrm{wi}}\right) \bar{c}_{\mathrm{g}}\right]} \cdot \frac{W_{\mathrm{p}}}{p_{\mathrm{i}}-p_{\mathrm{wf}}} .
\end{aligned}
$$

This equation can be rewritten as

$Y_{1}=b_{1}-m_{1} X_{1}$

where

$Y_{1}=\frac{q_{\mathrm{w}}}{p_{\mathrm{i}}-p_{\mathrm{wf}}}$

$X_{1}=\frac{W_{\mathrm{p}}}{p_{\mathrm{i}}-p_{\mathrm{wf}}}$

$b_{1}=\frac{0.543 k_{\mathrm{w}} h}{\mu_{\mathrm{w}} B_{\mathrm{w}} \ln \frac{0.472 r_{\mathrm{e}}}{r_{\mathrm{wc}}}}$

$m_{1}=\frac{b_{1} B_{\mathrm{w}}}{V_{\mathrm{pi}}\left[c_{\mathrm{p}}+S_{\mathrm{wi}} c_{\mathrm{w}}+\left(1-S_{\mathrm{wi}}\right) \bar{c}_{\mathrm{g}}\right]}$.

In the plot of $Y_{1}$ versus $X_{1}$, a straight line will be obtained and the slope and the $y$-intercept of the straight line will be determined.

Using pore compressibility, water compressibility, initial water saturation, the average gas compressibility, and the slope and $y$-intercept of the straight line, the control volume of this CBM reservoir can be determined as

$V_{\mathrm{pi}}=\frac{b_{1} B_{\mathrm{w}}}{m_{1}\left[c_{\mathrm{p}}+S_{\mathrm{wi}} c_{\mathrm{w}}+\left(1-S_{\mathrm{wi}}\right) \bar{c}_{\mathrm{g}}\right]}$.

Thus, the control radius of this CBM well will be determined through substituting the values of formation thickness, the initial porosity, and the control volume evaluated by Eq. (32) into the following equation: 
$r_{\mathrm{e}}=\sqrt{\frac{V_{\mathrm{pi}}}{\pi h \phi_{\mathrm{i}}}}$

Using reservoir thickness, the water formation volume factor, the water viscosity, the $y$-intercept of the straight line and the control radius evaluated by Eq. (33), the cleat permeability of the coal formation can be evaluated to be

$k_{\mathrm{w}}=\frac{b_{1} \mu_{\mathrm{w}} B_{\mathrm{w}} \ln \frac{0.472 r_{\mathrm{e}}}{r_{\mathrm{wc}}}}{0.543 h}$.

\subsection{Method 2}

Equation (24) can be organized to be the following form:

$\frac{p_{\mathrm{i}}-p_{\mathrm{wf}}}{q_{\mathrm{w}}}=\frac{\mu_{\mathrm{w}} B_{\mathrm{w}}}{0.543 k_{\mathrm{w}} h} \ln \frac{0.472 r_{\mathrm{e}}}{r_{\mathrm{wc}}}+\frac{B_{\mathrm{w}}}{V_{\mathrm{pi}}\left[c_{\mathrm{p}}+S_{\mathrm{wi}} c_{\mathrm{w}}+\left(1-S_{\mathrm{wi}}\right) \bar{c}_{\mathrm{g}}\right]} \frac{W_{\mathrm{p}}}{q_{\mathrm{w}}}$.

This equation can be rewritten as

$Y_{2}=b_{2}+m_{2} X_{2}$

where

$Y_{2}=\frac{p_{\mathrm{i}}-p_{\mathrm{wf}}}{q_{\mathrm{w}}}$

$X_{2}=\frac{W_{\mathrm{p}}}{q_{\mathrm{w}}}$

$b_{2}=\frac{\mu_{\mathrm{w}} B_{\mathrm{w}}}{0.543 k_{\mathrm{w}} h} \ln \frac{0.472 r_{\mathrm{e}}}{r_{\mathrm{wc}}}$

$m_{2}=\frac{B_{\mathrm{w}}}{V_{\mathrm{pi}}\left[c_{\mathrm{p}}+S_{\mathrm{wi}} c_{\mathrm{w}}+\left(1-S_{\mathrm{wi}}\right) \bar{c}_{\mathrm{g}}\right]}$.

In the plot of $Y_{2}$ versus $X_{2}$, a straight line will be obtained and the slope and the $y$-intercept of the straight line will be determined. The control volume and control radius of the CBM reservoir can be determined by using Eqs. (40) and (33). And the cleat permeability of the coal formation can be evaluated by substituting the value of the control radius into Eq. (39).

\subsection{Method 3}

Equation (24) can be transformed as the following equation:

$\frac{p_{\mathrm{i}}-p_{\mathrm{wf}}}{W_{\mathrm{p}}}=\frac{B_{\mathrm{w}}}{V_{\mathrm{pi}}\left[c_{\mathrm{p}}+S_{\mathrm{wi}} c_{\mathrm{w}}+\left(1-S_{\mathrm{wi}}\right) \bar{c}_{\mathrm{g}}\right]}+\frac{\mu_{\mathrm{w}} B_{\mathrm{w}}}{0.543 k_{\mathrm{w}} h} \ln \frac{0.472 r_{\mathrm{e}}}{r_{\mathrm{wc}}} \frac{q_{\mathrm{w}}}{W_{\mathrm{p}}}$.

This equation can be rewritten as
$Y_{3}=b_{3}+m_{3} X_{3}$

where

$Y_{3}=\frac{p_{\mathrm{i}}-p_{\mathrm{wf}}}{W_{\mathrm{p}}}$

$X_{3}=\frac{q_{\mathrm{w}}}{W_{\mathrm{p}}}$

$b_{3}=\frac{B_{\mathrm{w}}}{V_{\mathrm{pi}}\left[c_{\mathrm{p}}+S_{\mathrm{wi}} c_{\mathrm{w}}+\left(1-S_{\mathrm{wi}}\right) \bar{c}_{\mathrm{g}}\right]}$

$m_{3}=\frac{\mu_{\mathrm{w}} B_{\mathrm{w}}}{0.543 k_{\mathrm{w}} h} \ln \frac{0.472 r_{\mathrm{e}}}{r_{\mathrm{wc}}}$

Similarly, in the plot of $Y_{3}$ versus $X_{3}$, a straight line will be obtained and the slope and $y$-intercept of the straight line will be determined. Similar to the above methods, the control volume, control radius, and the cleat permeability of the CBM reservoir can be determined by using Eqs. (45), (33), and (46).

\subsection{Method 4}

Rearranging Eq. (23), the bottom-hole pressure can be expressed as

$p_{\mathrm{wf}}=p_{\mathrm{i}}-\frac{W_{\mathrm{p}} B_{\mathrm{w}}-W_{\mathrm{e}}}{V_{\mathrm{pi}}\left[c_{\mathrm{p}}+S_{\mathrm{wi}} c_{\mathrm{w}}+\left(1-S_{\mathrm{wi}}\right) \bar{c}_{\mathrm{g}}\right]}-\frac{\mu_{\mathrm{w}} B_{\mathrm{w}} q_{\mathrm{w}}}{0.543 k_{\mathrm{w}} h} \ln \frac{0.472 r_{\mathrm{e}}}{r_{\mathrm{wc}}}$.

The bottom-hole pressure at the last time step (for instance, yesterday) can be expressed as

$$
\begin{aligned}
p_{\mathrm{wf},(j-1)}= & p_{\mathrm{i}}-\frac{W_{\mathrm{p},(j-1)} B_{\mathrm{w}}-W_{\mathrm{e}}}{V_{\mathrm{pi}}\left[c_{\mathrm{p}}+S_{\mathrm{wi}} c_{\mathrm{w}}+\left(1-S_{\mathrm{wi}}\right) \bar{c}_{\mathrm{g}}\right]} \\
& -\frac{\mu_{\mathrm{w}} B_{\mathrm{w}} q_{\mathrm{w},(j-1)}}{0.543 k_{\mathrm{w}} h} \ln \frac{0.472 r_{\mathrm{e}}}{r_{\mathrm{wc}}} .
\end{aligned}
$$

The bottom-hole pressure at the current state (for instance, today) can be expressed as

$p_{\mathrm{wf},(j)}=p_{\mathrm{i}}-\frac{W_{\mathrm{p},(j)} B_{\mathrm{w}}-W_{\mathrm{e}}}{V_{\mathrm{pi}}\left[c_{\mathrm{p}}+S_{\mathrm{wi}} c_{\mathrm{w}}+\left(1-S_{\mathrm{wi}}\right) \bar{c}_{\mathrm{g}}\right]}-\frac{\mu_{\mathrm{w}} B_{\mathrm{w}} q_{\mathrm{w},(j)}}{0.543 k_{\mathrm{w}} h} \ln \frac{0.472 r_{\mathrm{e}}}{r_{\mathrm{wc}}}$.

Subtracting Eqs. (49) from (48) yields 
$p_{\mathrm{wf},(j-1)}-p_{\mathrm{wf},(j)}=\frac{\left(W_{\mathrm{p},(j)}-W_{\mathrm{p},(j-1)}\right) B_{\mathrm{w}}}{V_{\mathrm{pi}}\left[c_{\mathrm{p}}+S_{\mathrm{wi}} c_{\mathrm{w}}+\left(1-S_{\mathrm{wi}}\right) \bar{c}_{\mathrm{g}}\right]}+\frac{\mu_{\mathrm{w}} B_{\mathrm{w}} \ln \frac{0.472 r_{\mathrm{e}}}{r_{\mathrm{wc}}}}{0.543 k_{\mathrm{w}} h}\left(q_{\mathrm{w},(j)}-q_{\mathrm{w},(j-1)}\right)$.

Because the product of water production rate at the current state and the time step $\delta t$ plus the cumulative water production at the last time step is equal to the cumulative water production at the current state, the following equation can be derived:

$W_{\mathrm{p},(j)}-W_{\mathrm{p},(j-1)}=q_{\mathrm{w},(j)} \cdot \delta t$

where $\delta t$ is the time step, which is often set as 1 day because the dynamic performance data of CBM wells are daily data usually.

So, Eq. (50) can be expressed as

$p_{\mathrm{wf},(j-1)}-p_{\mathrm{wf},(j)}=\left\{\frac{B_{\mathrm{w}} \delta t}{V_{\mathrm{pi}}\left[c_{\mathrm{p}}+S_{\mathrm{wi}} c_{\mathrm{w}}+\left(1-S_{\mathrm{wi}}\right) \bar{c}_{\mathrm{g}}\right]}+\frac{\mu_{\mathrm{w}} B_{\mathrm{w}} \ln \frac{0.472 r_{\mathrm{e}}}{r_{\mathrm{wc}}}}{0.543 k_{\mathrm{w}} h}\right\} q_{\mathrm{w},(j)}-\frac{\mu_{\mathrm{w}} B_{\mathrm{w}} \ln \frac{0.472 r_{\mathrm{e}}}{r_{\mathrm{wc}}}}{0.543 k_{\mathrm{w}} h} q_{\mathrm{w},(j-1)}$.

Similarly, in the plot of $Y_{4}$ versus $X_{4}$, a straight line will be obtained. The slope and $y$-intercept of the straight line will be determined by fitting this straight line with linear relationship. Then the control volume, control radius, and the cleat permeability of the CBM reservoir can be determined by substituting the fitted slope and $y$-intercept of the straight line into Eqs. (58), (33), and (57), respectively.

$$
b_{4}=\frac{B_{\mathrm{w}} \delta t}{V_{\mathrm{pi}}\left[c_{\mathrm{p}}+S_{\mathrm{wi}} c_{\mathrm{w}}+\left(1-S_{\mathrm{wi}}\right) \bar{c}_{\mathrm{g}}\right]}+m_{4} \text {. }
$$

Finally, the following equation is derived:

$\frac{p_{\mathrm{wf},(j-1)}-p_{\mathrm{wf},(j)}}{q_{\mathrm{w},(j)}}=\left\{\frac{B_{\mathrm{w}} \delta t}{V_{\mathrm{pi}}\left[c_{\mathrm{p}}+S_{\mathrm{wi}} c_{\mathrm{w}}+\left(1-S_{\mathrm{wi}}\right) \bar{c}_{\mathrm{g}}\right]}+\frac{\mu_{\mathrm{w}} B_{\mathrm{w}} \ln \frac{0.472 r_{\mathrm{e}}}{r_{\mathrm{wc}}}}{0.543 k_{\mathrm{w}} h}\right\}-\frac{\mu_{\mathrm{w}} B_{\mathrm{w}} \ln \frac{0.472 r_{\mathrm{e}}}{r_{\mathrm{wc}}}}{0.543 k_{\mathrm{w}} h} \frac{q_{\mathrm{w},(j-1)}}{q_{\mathrm{w},(j)}}$. 


$$
\frac{\int_{0}^{t}\left(p_{\mathrm{i}}-p_{\mathrm{wf}}\right) \mathrm{d} t}{W_{\mathrm{p}}}=\frac{B_{\mathrm{w}}}{V_{\mathrm{pi}}\left[c_{\mathrm{p}}+S_{\mathrm{wi}} c_{\mathrm{w}}+\left(1-S_{\mathrm{wi}}\right) \bar{c}_{\mathrm{g}}\right]} \frac{\int_{0}^{t} W_{\mathrm{p}} \mathrm{d} t}{W_{\mathrm{p}}}+\frac{\mu_{\mathrm{w}} B_{\mathrm{w}}}{0.543 k_{\mathrm{w}} h} \ln \frac{0.472 r_{\mathrm{e}}}{r_{\mathrm{wc}}} .
$$

Equation (60) can be seen as a linear equation:

$Y_{5}=m_{5} X_{5}+b_{5}$

where

$Y_{5}=\frac{\int_{0}^{t}\left(p_{\mathrm{i}}-p_{\mathrm{wf}}\right) \mathrm{d} t}{W_{\mathrm{p}}}$

$X_{5}=\frac{\int_{0}^{t} W_{\mathrm{p}} \mathrm{d} t}{W_{\mathrm{p}}}$

$m_{5}=\frac{B_{\mathrm{w}}}{V_{\mathrm{pi}}\left[c_{\mathrm{p}}+S_{\mathrm{wi}} c_{\mathrm{w}}+\left(1-S_{\mathrm{wi}}\right) \bar{c}_{\mathrm{g}}\right]}$

$b_{5}=\frac{\mu_{\mathrm{w}} B_{\mathrm{w}}}{0.543 k_{\mathrm{w}} h} \ln \frac{0.472 r_{\mathrm{e}}}{r_{\mathrm{wc}}}$.

It can be seen from the above derivation that we only need to obtain the thickness of the reservoir around the CBM well, the water formation volume factor, the water viscosity, the bottom-hole pressure during the dewatering period and the water production data, then the control pore volume of this CBM reservoir and the initial reservoir permeability can be easily extrapolated. The detailed data processing steps are as follows:

Substituting the cumulative water production data at different production times into Eq. (64), a set of data that changes over time can be obtained, which is recorded as $X_{5}$.

Substituting the initial reservoir pressure, bottom-hole pressure, and the cumulative water production into Eq. (63), we can obtain another set of data $Y_{5}$ that varies with production time.

Depicting $X_{5}$ and $Y_{5}$ in a rectangular coordinate system and fitting the data with a linear trend line, a linear equation with the same expression as Eq. (62) can be obtained. The slope and $y$-intercept of the fitted trend line in the coordinate system are $m_{5}$ and $b_{5}$ in Eq. (62), respectively.

The control pore volume of this CBM reservoir can be calculated by substituting pore compressibility, water compressibility, initial water saturation, the average gas compressibility, and the slope of straight line $m_{5}$ into Eq. (65).
Thus, the control radius of this CBM well will be determined by substituting the formation thickness, the initial porosity, and the calculated control volume into Eq. (33).

The initial permeability around a CBM well can be calculated by substituting the reservoir thickness, the water formation volume factor, the water viscosity, the control radius of this CBM well, and the $y$-intercept of straight line $b_{5}$ into Eq. (66).

After the control volume and the permeability of this CBM reservoir are evaluated using the above five methods, the initial free gas reserve and the initial water reserve can be determined using Eqs. (6) and (7), respectively. Substituting the evaluated control volume, initial porosity, Langmuir volume, Langmuir pressure, and critical desorption pressure into Eq. (67), the initial adsorbed gas reserve can be determined.

$G_{\mathrm{a}}=\frac{V_{\mathrm{pi}}}{\phi_{\mathrm{i}}} \cdot \frac{V_{\mathrm{L}} p_{\mathrm{d}}}{p_{\mathrm{d}}+p_{\mathrm{L}}}$.

Table 1 The formation and fluid properties for Case I and Case II

\begin{tabular}{lll}
\hline Parameters & Values & \\
\cline { 2 - 3 } & Case I & Case II \\
\hline Initial water saturation $S_{\mathrm{wi}}$, fraction & 1 & 0.95 \\
Critical flowing gas saturation $S_{\mathrm{gc}}$, fraction & 0.03 & 0.15 \\
Control radius $r_{\mathrm{e}}, \mathrm{m}$ & 200 & 200 \\
Wellbore radius $r_{\mathrm{w}}, \mathrm{m}$ & 0.1 & 0.1 \\
Coal formation thickness $h, \mathrm{~m}$ & 6 & 6 \\
Porosity of coal formation $\phi_{\mathrm{i}}$, fraction & 0.03 & 0.03 \\
Water viscosity $\mu_{\mathrm{w}}, \mathrm{mPa} \mathrm{s}$ & 1 & 1 \\
Water volume factor $B_{\mathrm{w}}, \mathrm{sm}^{3} / \mathrm{m}^{3}$ & 1 & 1 \\
Pore compressibility $c_{\mathrm{p}}, \mathrm{MPa}{ }^{-1}$ & 0.01087 & 0.01087 \\
Water compressibility $c_{\mathrm{w}}, \mathrm{MPa}{ }^{-1}$ & 0.000435 & 0.000435 \\
Initial reservoir pressure $p_{\mathrm{i}}, \mathrm{MPa}$ & 5.26 & 5.26 \\
Critical desorption pressure $p_{\mathrm{d}}, \mathrm{MPa}$ & 2 & 2 \\
Langmuir volume $V_{\mathrm{L}}, \mathrm{m}^{3} / \mathrm{m}^{3}$ & 20 & 20 \\
Langmuir pressure $p_{\mathrm{L}}, \mathrm{MPa}$ & 2 & 2 \\
Permeability of coal formation $k, \mathrm{mD}$ & 5 & 5 \\
Coal formation temperature $T,{ }^{\circ} \mathrm{C}$ & 32 & 32 \\
Gas specific gravity, dimensionless & 0.552 & 0.552 \\
Initial gas deviation factor $Z_{\mathrm{i}}$, dimensionless & 0.94 & 0.94 \\
\hline
\end{tabular}




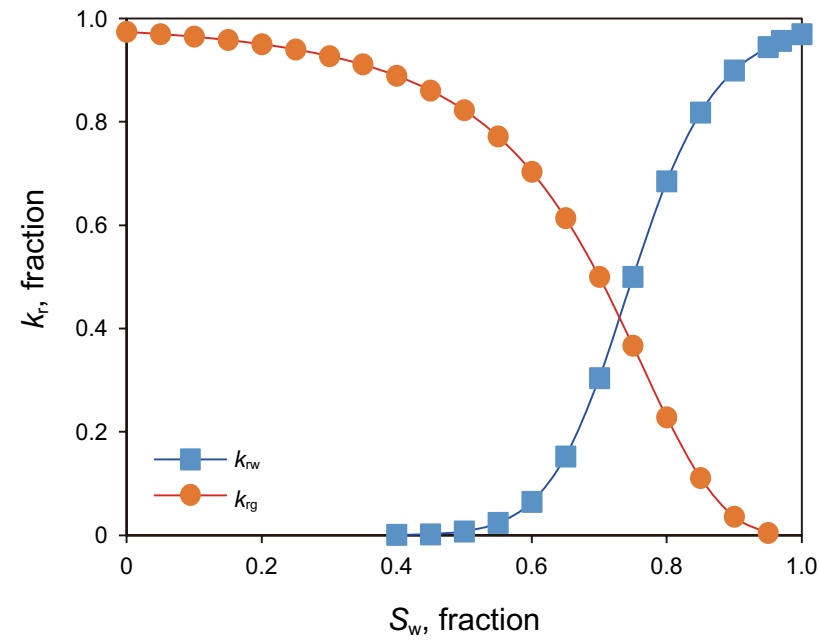

(a) Case I

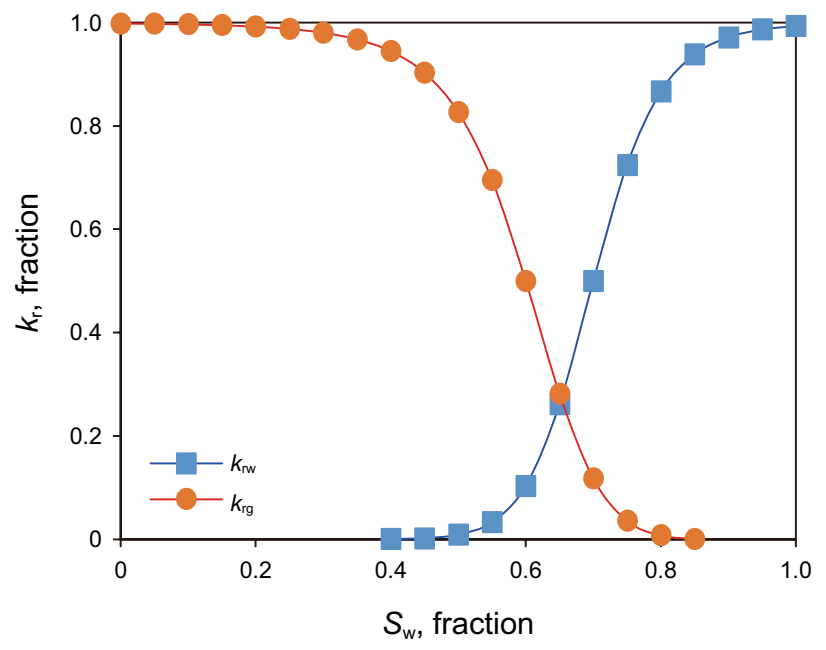

(b) Case II

Fig. 1 Relative permeability curves of water and gas for Case I (a) and Case II (b). The critical flowing gas saturation is 0.03 and 0.15 for Case I and Case II, respectively

\section{Validation}

A CBM dynamic analysis software developed by Shi et al. (2018a, 2019b) is used to verify the proposed FMBE methods. The CBM dynamic analysis software has been validated against commercial reservoir simulators, such as CMG and Eclipse, and shown to be effective and rational based on some field applications in the Hancheng CBM reservoir, Baode CBM reservoir, Muai CBM reservoir, Qimei CBM reservoir, Liulin CBM reservoir, etc. Thus, it is reasonable to apply this software to verify the proposed FMBE methods.
In this work, two case studies are conducted based on the formation and fluid properties as shown in Table 1. The rest parameters for these two cases are the same except of the initial water saturation, critical flowing gas saturation, and relative permeability curves. One is for an undersaturated CBM reservoir without any free gas, i.e., the initial water saturation is 1 ; the other is for an undersaturated CBM reservoir with 0.05 of free gas in gas saturation. The dynamic analysis software is applied to generate the water and gas production histories by inputting the given bottom-hole pressure schedule and formation and fluid parameters. Then the

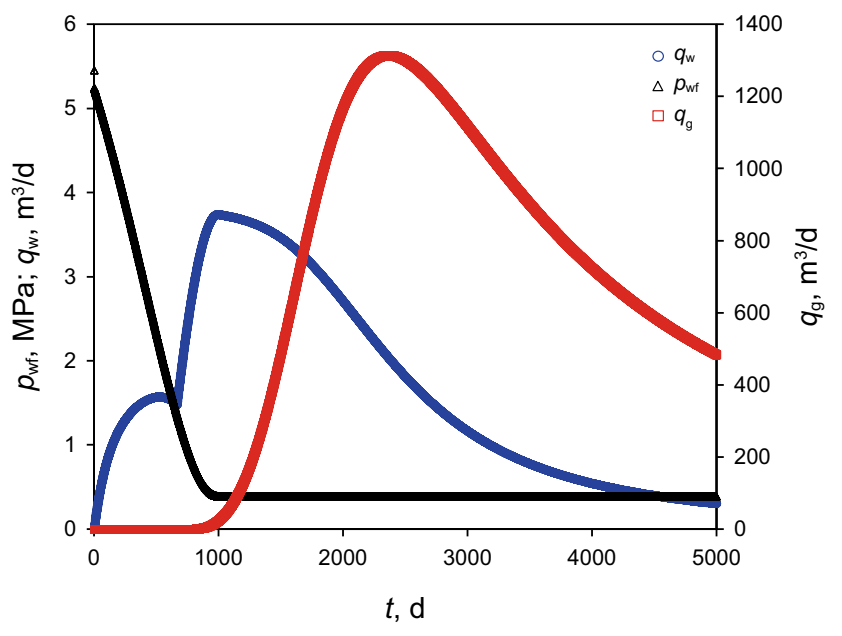

(a) The whole production history

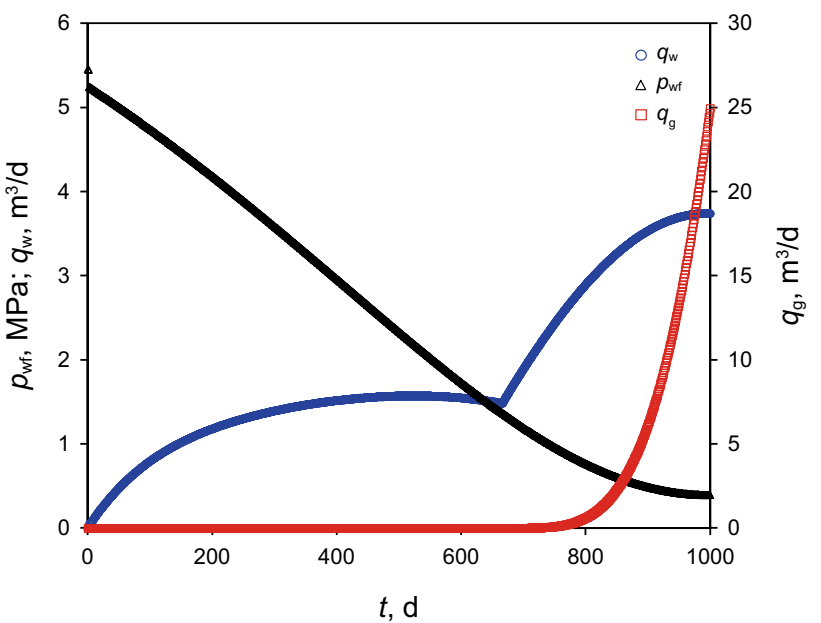

(b) The production at the dewatering stage

Fig. 2 Water and gas production rates generated from the dynamic analysis software produced at a given bottom-hole pressure schedule for Case I 


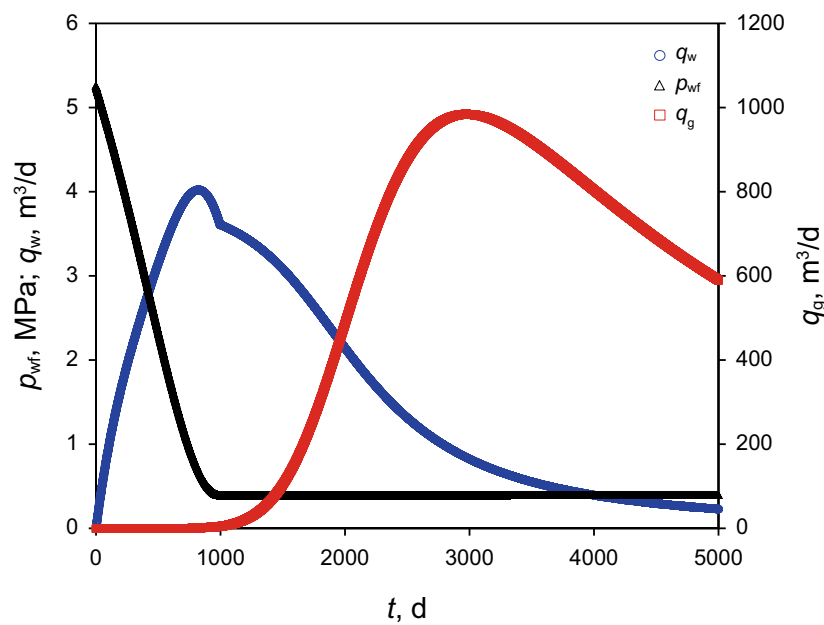

(a) The whole production history

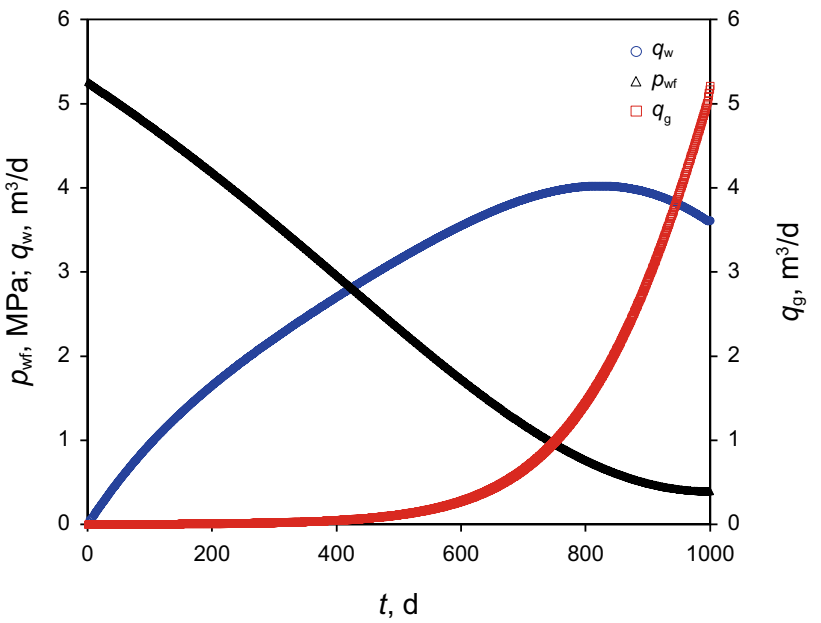

(b) The production at the dewatering stage

Fig. 3 Water and gas production rates generated from the dynamic analysis software produced at a given bottom-hole pressure schedule for Case II

output water production rate and the input bottom-hole pressure are used to test the effectiveness of the proposed five FMBE methods. If the straight-line relationships between $Y$ and $X$ are good and the evaluated results including the control area, water reserve, free gas reserve, adsorbed gas reserve, OGIP, and permeability of the coal formation are coincident with the actual values used in the dynamic analysis software, the proposed FMBE methods will be proven to be effective, rational, and applicable for evaluating both reserve and permeability of undersaturated CBM reservoirs.

The relative permeability curves used for Case I and Case II are shown in Fig. 1. The CBM wells for these two cases are produced by controlling the bottom-hole pressure as shown black triangles in Figs. 2 and 3. On the basis of the formation and fluid parameters in Table 1 and the given bottom-hole pressure schedules, water and gas production rates for Case I and Case II are generated from the dynamic analysis software, which are shown in Figs. 2 and 3, respectively.

Using the water production rates before the gas desorption stage generated from the software, which are shown as blue circles before 500 days of production in Fig. $2 \mathrm{~b}$ for Case I, blue circles before 400 days of production in Fig. $3 \mathrm{~b}$ for Case II, and the given bottom-hole pressure schedules in Fig. 2b for Case I and Fig. 3b for Case II, the proposed five FMBE methods are applied to form the straight lines of $Y$ versus $X$ for these two cases. Then, the control radius of these two CBM wells, water reserve, OGIP, and permeability of the coal formation are evaluated from the slopes and $y$-intercepts of these straight lines on the basis of some given formation and fluid parameters except the control radius and the permeability for these two cases.

Figures 4 and 5 present the fitting plots by these five FMBE methods for Case I and Case II. Tables 2 and 3 show the fitting results from these five FMBE methods and the actual data for Case I and Case II, respectively. From Figs. 4 and 5 , it can be clearly seen that the straight-line relationships for the proposed five FMBE methods are very excellent for these two cases. From the comparisons of results between the evaluated values and actual values, as shown in Table 2 for Case I and Table 3 for Case II, the evaluated reserves and permeability are nearly equal to the actual values for Case I, and within $1 \%$ in relative errors of reserve evaluations and $2 \%$ in relative errors of permeability evaluations for Case II, indicating that the proposed five FMBE methods are effective and rational even for $\mathrm{CBM}$ reservoirs with small amount of free gas.

For Case II, because there is a small amount of free gas, during the dewatering stage, the gas expansion effect cannot be ignored. Since by using the water production data and bottom-hole pressure from 40 and 262 days, the best fitting results for the straight-line relationship between $Y$ and $X$ are obtained, the bottom-hole pressure history between 40 and 262 days is used to calculate the average gas compressibility. For this case, the average value of the bottom-hole pressure from 40 to 262 days is $4.4641 \mathrm{MPa}$, the average reservoir pressure is calculated to be $4.8620 \mathrm{MPa}, Z$ factor is 0.9293 at this average reservoir pressure, $\partial Z / \partial \bar{p}$ is -0.01271 from the plot of $Z$ factor versus pressure as shown in Fig. 6, and thus, the average gas compressibility is calculated to be $0.2194 \mathrm{MPa}^{-1}$.

If the initial water saturation is mistaken as 1 for Case II, using the bottom-hole pressure and water production data in Fig. 3b, the straight-line relationship in the plots of $Y$ versus $X$ is still good when using the proposed five FMBE methods, but the evaluated results including the control radius, water reserve, OGIP, and permeability largely deviate from 


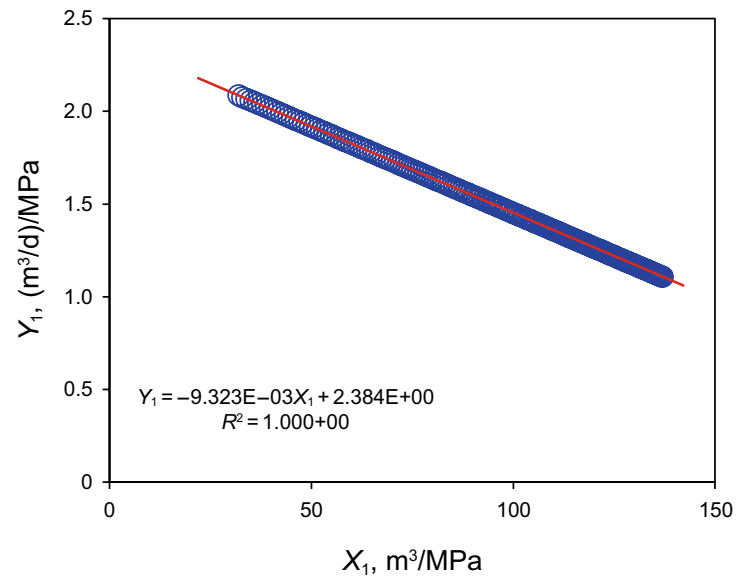

(a) The FMBE method 1

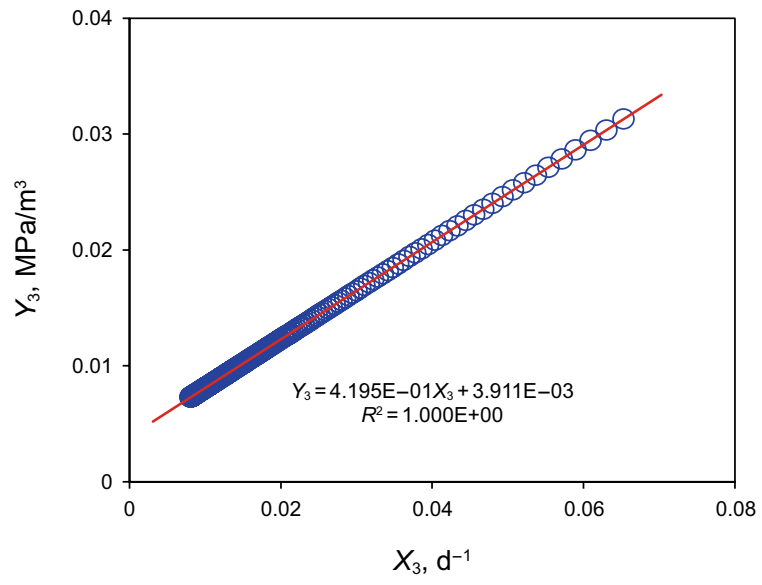

(c) The FMBE method 3

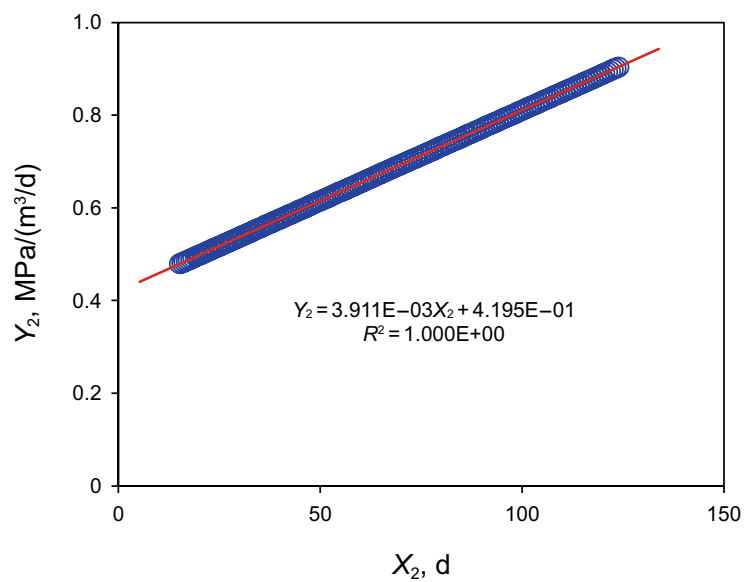

(b) The FMBE method 2

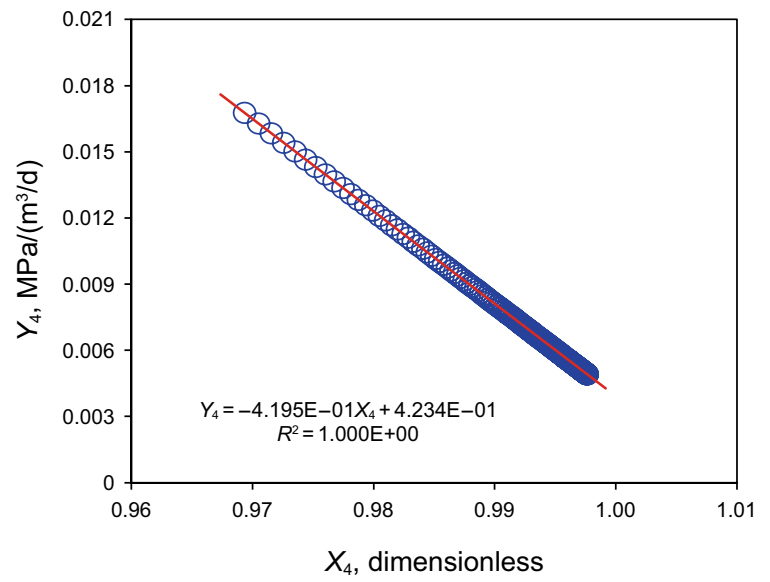

(d) The FMBE method 4

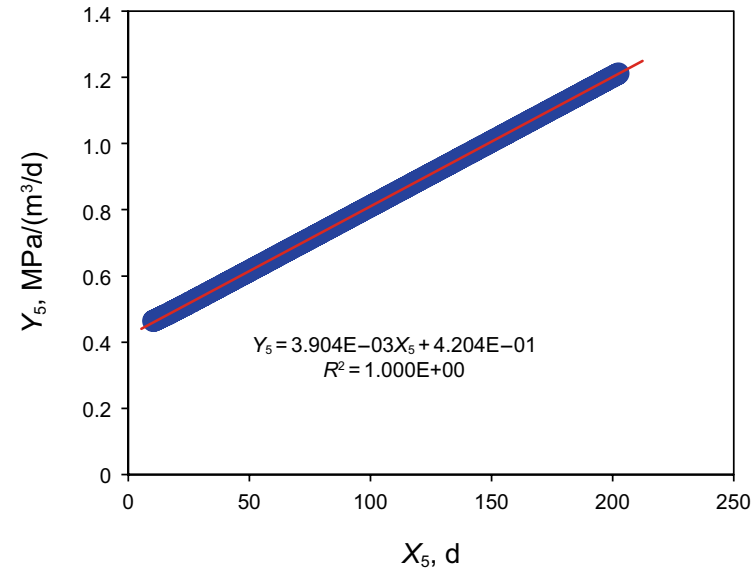

(e) The FMBE method 5

Fig. 4 The fitting plots by these five FMBE methods for Case I. a $X_{1}$ is calculated by Eq. (29), and $Y_{1}$ is calculated by Eq. (28); $\mathbf{b} X_{2}$ is calculated by Eq. (38), and $Y_{2}$ is calculated by Eq. (37); $\mathbf{c} X_{3}$ is calculated by Eq. (44), and $Y_{3}$ is calculated by Eq. (43); $\mathbf{d} X_{4}$ is calculated by Eq. (56), and $Y_{4}$ is calculated by Eq. (55); $\mathbf{e} X_{5}$ is calculated by Eq. (64), and $Y_{5}$ is calculated by Eq. (63) 


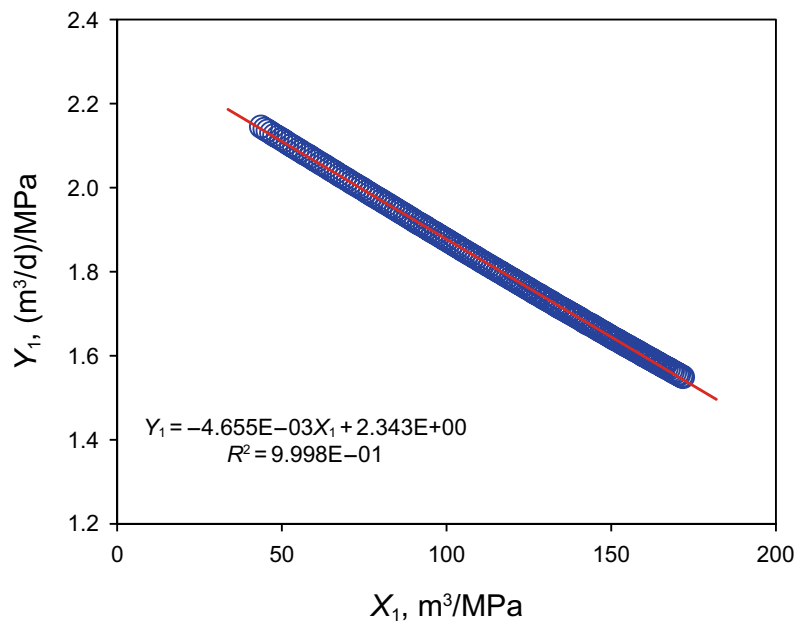

(a) The FMBE method 1

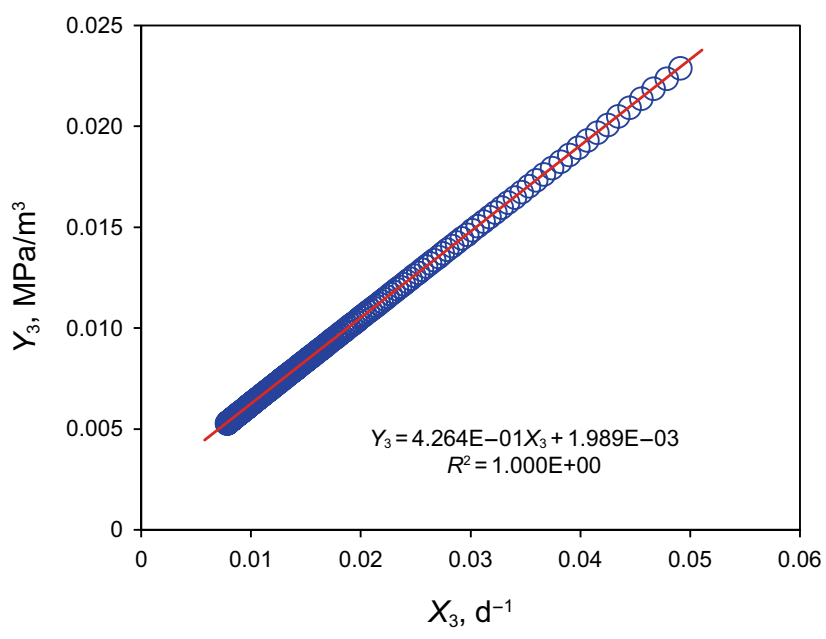

(c) The FMBE method 3

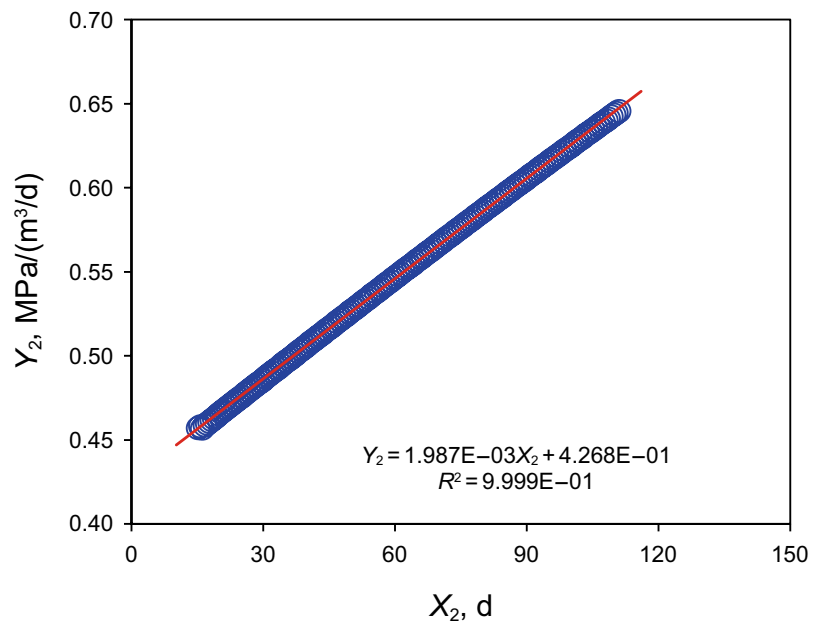

(b) The FMBE method 2

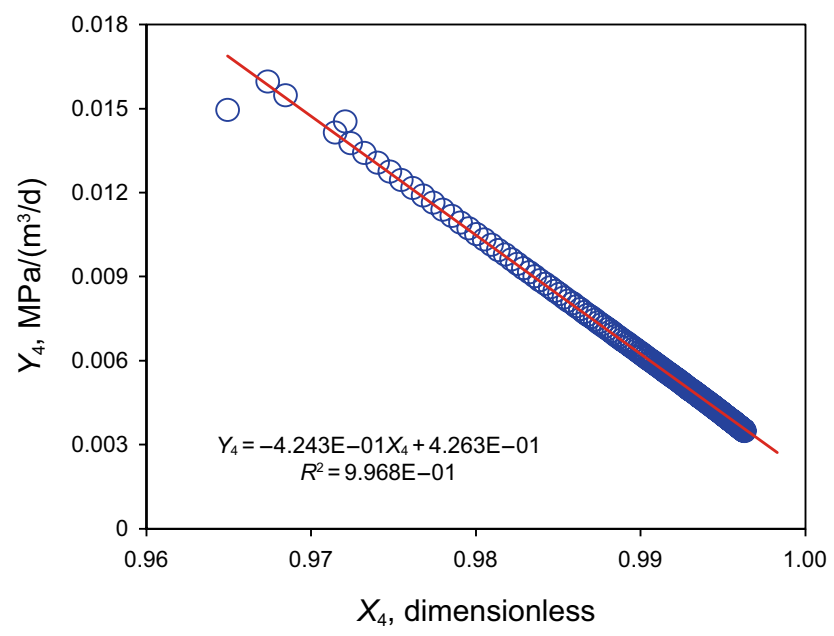

(d) The FMBE method 4

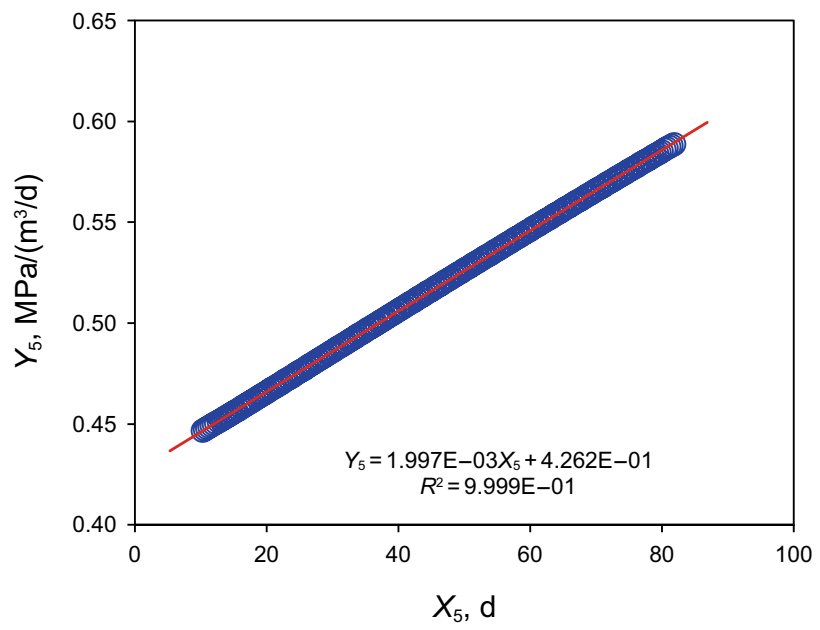

(e) The FMBE method 5

Fig. 5 The fitting plots by these five FMBE methods for Case II. a $X_{1}$ is calculated by Eq. (29), and $Y_{1}$ is calculated by Eq. (28); b $X_{2}$ is calculated by Eq. (38), and $Y_{2}$ is calculated by Eq. (37); c $X_{3}$ is calculated by Eq. (44), and $Y_{3}$ is calculated by Eq. (43); $\mathbf{d} X_{4}$ is calculated by Eq. (56), and $Y_{4}$ is calculated by Eq. (55); $\mathbf{e} X_{5}$ is calculated by Eq. (64), and $Y_{5}$ is calculated by Eq. (63) 
Table 2 The fitting results from the proposed five FMBE methods and the actual data for Case I

\begin{tabular}{lllllll}
\hline Parameters & Actual values & Method 1 & Method 2 & Method 3 & Method 4 \\
\hline Slope of the straight line $m$ & - & $9.323 \times 10^{-3}$ & $3.911 \times 10^{-3}$ & $4.195 \times 10^{-1}$ & $4.195 \times 10^{-1}$ & $3.904 \times 10^{-3}$ \\
$y$-intercept of the straight line $b$ & - & 2.384 & $4.195 \times 10^{-1}$ & $3.911 \times 10^{-3}$ & $4.234 \times 10^{-1}$ & $4.204 \times 10^{-1}$ \\
Control pore volume $V_{\mathrm{pi}}, \mathrm{m}^{3}$ & $22,619.467$ & $22,619.467$ & $22,619.467$ & $22,619.467$ & $22,619.427$ & $22,655.939$ \\
Control radius $r_{\mathrm{e}}, \mathrm{m}$ & 200.000 & 200.000 & 200.000 & 200.000 & 200.000 \\
Water reserve, $\mathrm{m}^{3}$ & $22,619.467$ & $22,619.467$ & $22,619.467$ & $22,619.467$ & $22,619.427$ & $22,655.939$ \\
Adsorbed gas reserve $G_{\mathrm{a}}, 10^{4} \mathrm{~m}^{3}$ & 753.982 & 753.982 & 753.982 & 753.982 & 753.981 & 755.198 \\
Free gas reserve $G_{\mathrm{f}}, 10^{4} \mathrm{~m}^{3}$ & 0 & 0 & 0 & 0 & 0 & 0 \\
OGIP, $10^{4} \mathrm{~m}^{3}$ & 753.982 & 753.982 & 753.982 & 753.982 & 753.981 & 755.198 \\
Permeability of coal formation $k, \mathrm{mD}$ & 5.000 & 5.013 & 5.013 & 5.013 & 5.013 & 5.002 \\
\hline
\end{tabular}

Table 3 The fitting results from the proposed five FMBE methods and the actual data for Case II

\begin{tabular}{lllllll}
\hline Parameters & Actual values & Method 1 & Method 2 & Method 3 & Method 4 & Method 5 \\
\hline Slope of the straight line $m$ & - & $4.655 \times 10^{-3}$ & $1.987 \times 10^{-3}$ & $4.264 \times 10^{-1}$ & $4.243 \times 10^{-1}$ & $1.997 \times 10^{-3}$ \\
$y$-intercept of the straight line $b$ & - & 2.343 & $4.268 \times 10^{-1}$ & $1.989 \times 10^{-3}$ & $4.263 \times 10^{-1}$ & $4.262 \times 10^{-1}$ \\
Control pore volume $V_{\mathrm{pi}}, \mathrm{m}^{3}$ & $22,619.467$ & $22,619.570$ & $22,618.819$ & $22,593.722$ & $22,470.651$ & $22,504.618$ \\
Control radius $r_{\mathrm{e}}, \mathrm{m}$ & 200.000 & 200.000 & 199.997 & 199.886 & 199.341 \\
Water reserve, $\mathrm{m}^{3}$ & $21,488.490$ & $21,488.592$ & $21,487.878$ & $21,464.037$ & $21,347.118$ & $21,379.387$ \\
Adsorbed gas reserve $G_{\mathrm{a}}, 10^{4} \mathrm{~m}^{3}$ & 753.982 & 753.986 & 753.961 & 753.124 & 749.022 & 750.154 \\
Free gas reserve $G_{\mathrm{f}}, 10^{4} \mathrm{~m}^{3}$ & 6.080 & 6.080 & 6.797 & 6.073 & 6.040 \\
OGIP, $10^{4} \mathrm{~m}^{3}$ & 760.062 & 760.065 & 760.040 & 759.197 & 755.062 & 7.049 \\
Permeability of coal formation $k, \mathrm{mD}$ & 5.000 & 4.926 & 4.927 & 4.930 & 4.953 & 4.932 \\
Relative error of OGIP, $\%$ & - & 0.000 & -0.003 & -0.114 & -0.658 & -0.508 \\
Relative error of water reserve, $\%$ & - & 0 & -1.481 & -1.467 & -1.397 & -0.658 \\
Relative error of permeability, $\%$ & - & & & -0.114 & -0.638
\end{tabular}

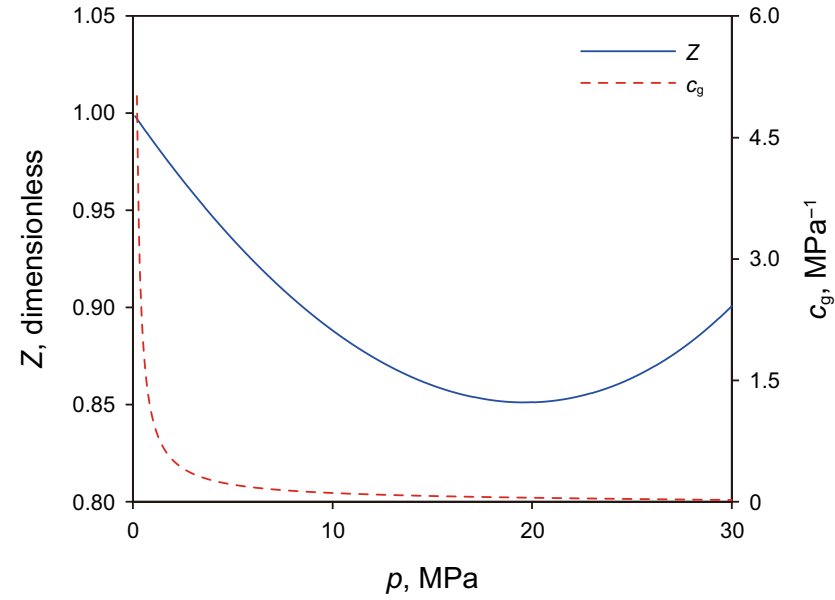

(a) The whole pressure range

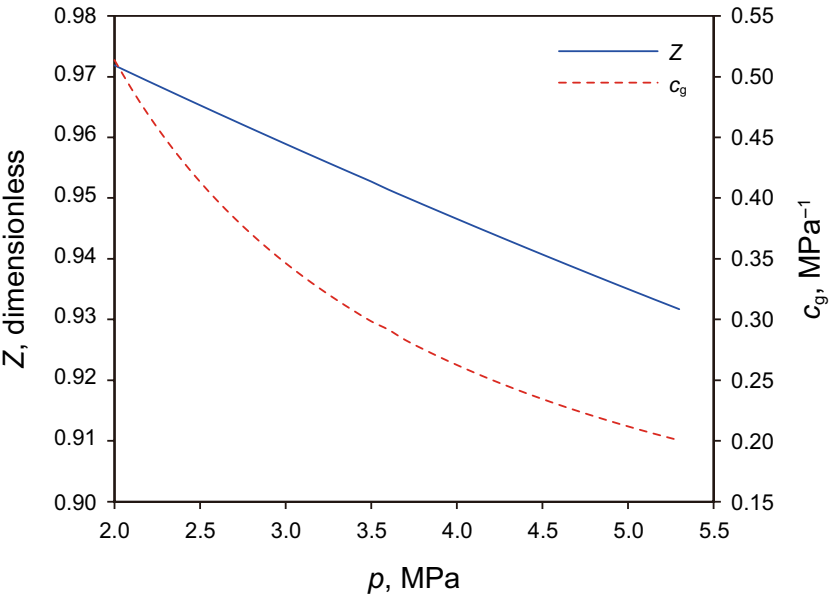

(b) Pressure from $p_{\mathrm{d}}$ to $p_{\mathrm{i}}$

Fig. 6 The plot of $Z$ factor of gas versus pressure for Case II and the field case. The gas specific gravity is 0.552 , and the coal formation temperature is $32{ }^{\circ} \mathrm{C}$ 
Table 4 A comparison between the actual data and those evaluated by the proposed five FMBE methods when ignoring free gas expansion for Case II

\begin{tabular}{|c|c|c|c|c|c|c|}
\hline Parameters & Actual values & Method 1 & Method 2 & Method 3 & Method 4 & Method 5 \\
\hline Control pore volume $V_{\mathrm{pi}}, \mathrm{m}^{3}$ & $22,619.467$ & $44,432.079$ & $44,520.965$ & $44,111.829$ & $44,229.102$ & $44,318.228$ \\
\hline Control radius $r_{\mathrm{e}}, \mathrm{m}$ & 200 & 280.309 & 280.589 & 279.297 & 279.668 & 279.950 \\
\hline Water reserve, $\mathrm{m}^{3}$ & $21,488.490$ & $44,432.079$ & $44,520.965$ & $44,111.829$ & $44,229.102$ & $44,318.228$ \\
\hline Adsorbed gas reserve $G_{\mathrm{a}}, 10^{4} \mathrm{~m}^{3}$ & 753.982 & 1481.069 & 1484.032 & 1470.394 & 1474.303 & 1477.274 \\
\hline Free gas reserve $G_{\mathrm{f}}, 10^{4} \mathrm{~m}^{3}$ & 6.080 & 0 & 0 & 0 & 0 & 0 \\
\hline OGIP, $10^{4} \mathrm{~m}^{3}$ & 760.062 & 1481.069 & 1484.032 & 1470.394 & 1474.303 & 1477.274 \\
\hline Permeability of coal formation $k, \mathrm{mD}$ & 5.000 & 5.172 & 5.170 & 5.179 & 5.19 & 5.175 \\
\hline Relative error of $r_{\mathrm{e}}, \%$ & - & 40.155 & 40.295 & 39.649 & 39.834 & 39.975 \\
\hline Relative error of water reserve, $\%$ & - & 106.771 & 107.185 & 105.281 & 105.827 & 106.242 \\
\hline Relative error of $G_{\mathrm{a}}, \%$ & - & 96.433 & 96.826 & 95.017 & 95.536 & 95.930 \\
\hline Relative error of OGIP, $\%$ & - & 94.862 & 95.251 & 93.457 & 93.971 & 94.362 \\
\hline Relative error of permeability, \% & - & 3.448 & 3.404 & 3.584 & 3.961 & 3.501 \\
\hline
\end{tabular}

Table 5 The formation and fluid properties for one well in the Muai CBM reservoir

\begin{tabular}{ll}
\hline Parameters & Values \\
\hline Initial water saturation $S_{\mathrm{wi}}$, fraction & 0.96 \\
Critical flowing gas saturation $S_{\mathrm{gc}}$, fraction & 0.15 \\
Equivalent wellbore radius $r_{\mathrm{wc}}, \mathrm{m}$ & 35 \\
Coal formation thickness $h, \mathrm{~m}$ & 6 \\
Porosity of coal formation $\phi_{\mathrm{i}}$, fraction & 0.013 \\
Water viscosity $\mu_{\mathrm{w}}, \mathrm{mPa} \cdot \mathrm{s}$ & 1 \\
Water volume factor, $\mathrm{sm}^{3} / \mathrm{m}^{3}$ & 1 \\
Pore compressibility $c_{\mathrm{p}}, \mathrm{MPa}^{-1}$ & 0.00423 \\
Water compressibility $c_{\mathrm{w}}, \mathrm{MPa}{ }^{-1}$ & 0.000435 \\
Initial reservoir pressure $p_{\mathrm{i}}, \mathrm{MPa}$ & 6.5 \\
Critical desorption pressure $p_{\mathrm{d}}, \mathrm{MPa}$ & 3 \\
Langmuir volume $V_{\mathrm{L}}, \mathrm{m}^{3} / \mathrm{m}^{3}$ & 32 \\
Langmuir pressure $p_{\mathrm{L}}, \mathrm{MPa}$ & 1.8 \\
Coal formation temperature $T,{ }^{\circ} \mathrm{C}$ & 32 \\
Gas specific gravity, dimensionless & 0.552 \\
Initial gas deviation factor $Z_{\mathrm{i}}$, dimensionless & 0.925 \\
\hline
\end{tabular}

the actual values, as shown in Table 4 . The evaluated control radius is larger than the actual control radius of this CBM well up to $40 \%$ of the actual value, the evaluated water reserves are more than two times the actual values, and the evaluated initial adsorbed gas reserve and OGIP are larger than the corresponding actual values up to $96 \%$ and $94 \%$, respectively. In addition, the permeability is also overestimated. Therefore, the effect of gas expansion on the reserve and permeability evaluations using FMBE methods is very sensitive and important; so it cannot be ignored. Even though the amount of free gas is small, its expansion effect on water production rate is dramatic.

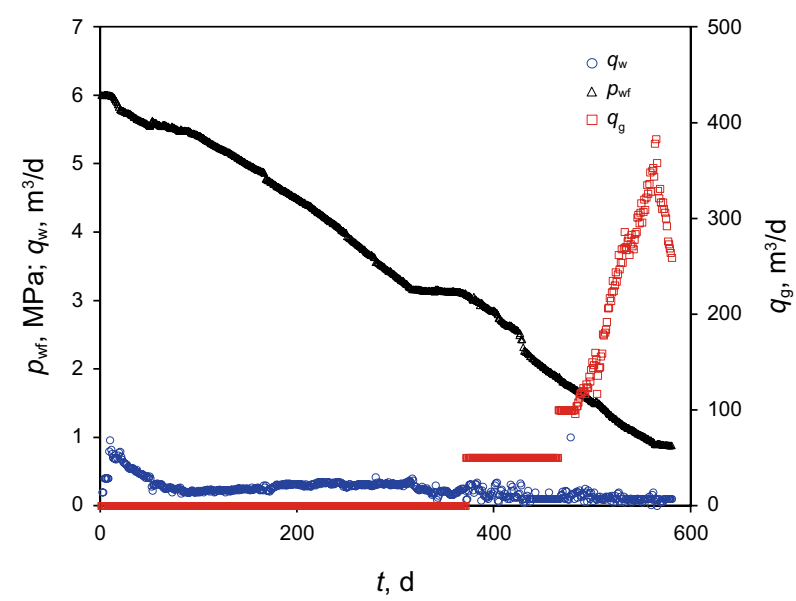

Fig. 7 The actual bottom-hole pressure history and the corresponding water and gas production rate histories of the well in the Muai CBM reservoir

\section{Field application}

After validation of the proposed five FMBE methods, it is necessary to test their effectiveness in field application. One well in the Muai CBM reservoir is taken as an example; the formation and fluid properties are listed in Table 5. The gas and water relative permeability curves are shown in Fig. 1 b. The actual bottom-hole pressure history and the corresponding water and gas production rate histories are shown in Fig. 7.

From Fig. 7, it can be clearly seen that before 300 days, the bottom-hole pressure is higher than the critical desorption pressure and there is no gas production. Thus, the bottom-hole pressure and water production rate data before 300 days are selected, and the proposed five FMBE methods 


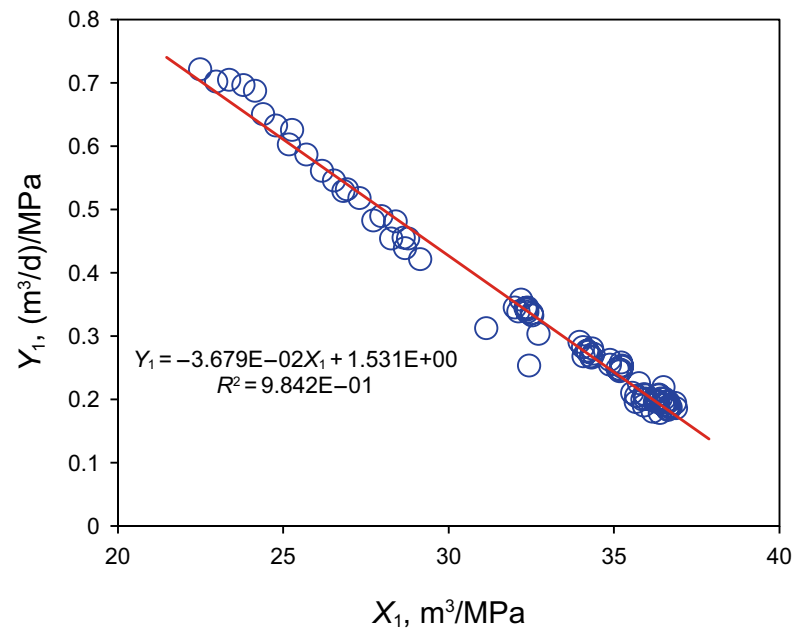

(a) The FMBE method 1

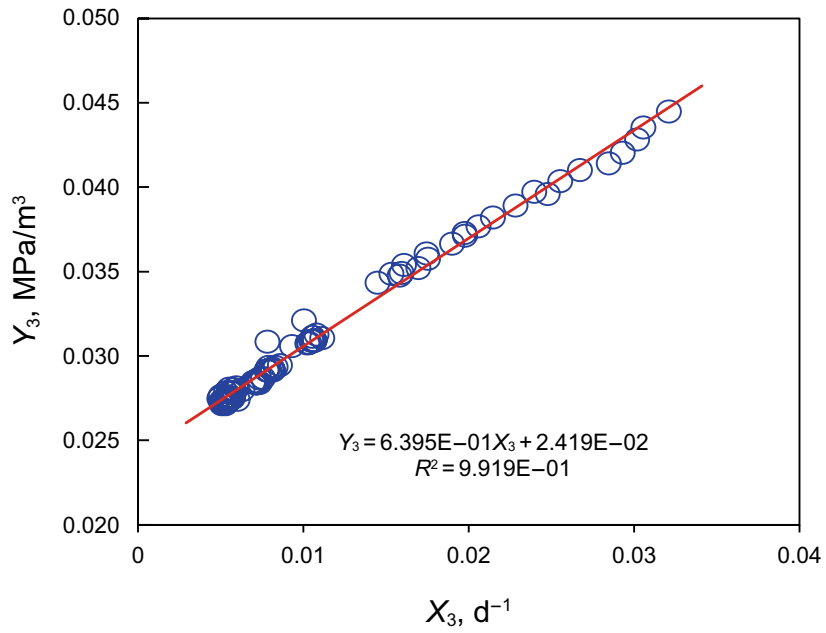

(c) The FMBE method 3

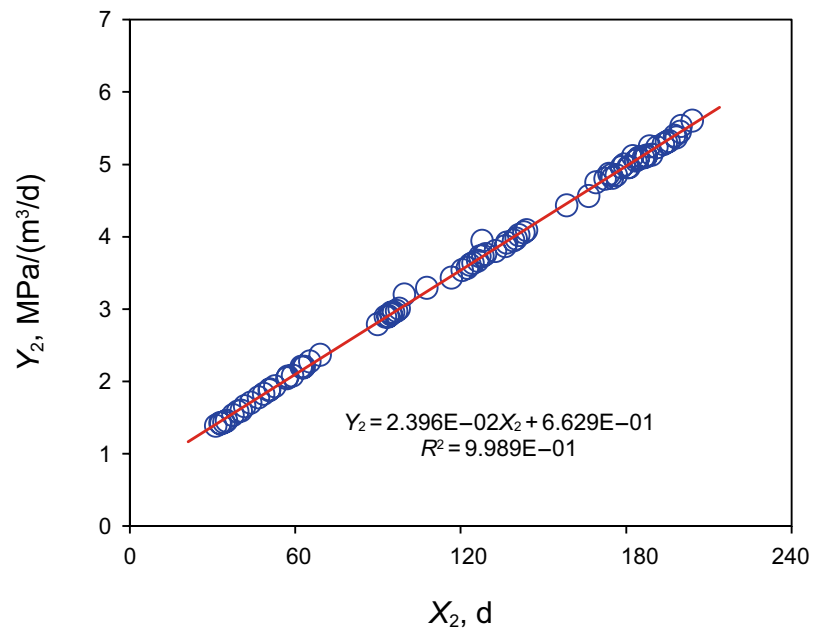

(b) The FMBE method 2

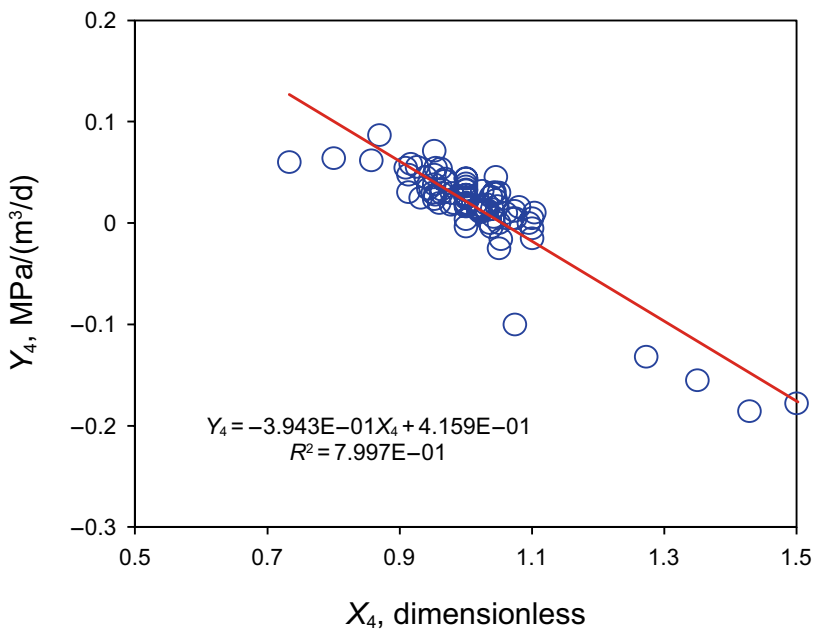

(d) The FMBE method 4

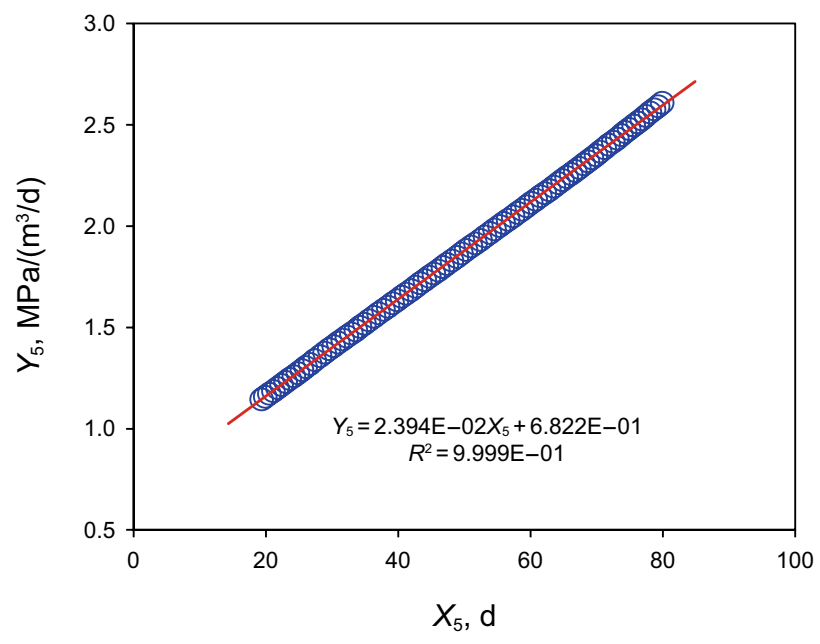

(e) The FMBE method 5

Fig. 8 The fitting plots by these five FMBE methods for the field case. a $X_{1}$ is calculated by Eq. (29), and $Y_{1}$ is calculated by Eq. (28); b $X_{2}$ is calculated by Eq. (38), and $Y_{2}$ is calculated by Eq. (37); c $X_{3}$ is calculated by Eq. (44), and $Y_{3}$ is calculated by Eq. (43); d $X_{4}$ is calculated by Eq. (56), and $Y_{4}$ is calculated by Eq. (55); e $X_{5}$ is calculated by Eq. (64), and $Y_{5}$ is calculated by Eq. (63) 
Table 6 The fitting results from the proposed five FMBE methods for the field case

\begin{tabular}{llllll}
\hline Parameters & Method 1 & Method 2 & Method 3 & Method 4 & Method 5 \\
\hline Slope of the straight line $m$ & $3.679 \times 10^{-2}$ & $2.395 \times 10^{-2}$ & $6.395 \times 10^{-1}$ & $3.943 \times 10^{-1}$ & $2.394 \times 10^{-2}$ \\
$y$-intercept of the straight line $b$ & 1.531 & $6.288 \times 10^{-1}$ & $2.419 \times 10^{-2}$ & $4.159 \times 10^{-1}$ & $6.822 \times 10^{-1}$ \\
Control pore volume $V_{\mathrm{pi}}, \mathrm{m}^{3}$ & 3503.286 & 3515.230 & 3481.430 & 3892.941 & 3516.496 \\
Control radius $r_{\mathrm{e}}, \mathrm{m}$ & 119.568 & 119.772 & 119.195 & 126.042 & 119.793 \\
Water reserve, $\mathrm{m}^{3}$ & 3363.154 & 3374.621 & 3342.173 & 3737.224 \\
Adsorbed gas reserve $G_{\mathrm{a}}, 10^{4} \mathrm{~m}^{3}$ & 538.967 & 540.805 & 535.605 & 598.914 & 3375.836 \\
Free gas reserve $G_{\mathrm{f}}, 10^{4} \mathrm{~m}^{3}$ & 0.934 & 0.338 & 0.928 & 540.999 \\
OGIP, $10^{4} \mathrm{~m}^{3}$ & 539.901 & 541.742 & 536.533 & 599.952 & 0.937 \\
Permeability of coal formation $k, \mathrm{mD}$ & 0.225 & 0.234 & 0.228 & 541.937 \\
\hline
\end{tabular}

are applied to generate the straight lines of $Y$ versus $X$. Finally, the bottom-hole pressure and water production rate data from 30 days to 148 days are selected to make sure that pseudo-steady state has been achieved and avoided the influence of fracturing fluid flowback. Figure 8 presents the fitting plots by these five FMBE methods for this field case. From Fig. 8, it can be seen that the straight-line relationship of methods $1,2,3$, and 5 is very good, while the straight-line relationship of method 4 is not good; the reason is that the water production rate nearly remains constant during dewatering, as shown in Fig. 7, resulting in $X$ values close to 1.

The average gas compressibility is calculated using the average reservoir pressure and $Z$ factor plot versus pressure, where the average reservoir pressure is calculated using the initial reservoir pressure and the average value of bottom-hole pressure from 30 to 148 days. For this field case, the average value of the bottom-hole pressure from 30 to 148 days is $5.4175 \mathrm{MPa}$, the average reservoir pressure is calculated to be $5.9588 \mathrm{MPa}, Z$ factor is 0.9159 at this average reservoir pressure, $\partial Z / \partial \bar{p}$ is -0.0119 from the plot of $Z$ factor versus pressure which is shown in Fig. 6; thus, the average gas compressibility is calculated to be $0.1807 \mathrm{MPa}^{-1}$.

Then, on the basis of the formation and fluid parameters in Table 5 and calculated average gas compressibility, using the slope and $y$-intercept of these straight lines, the control radius of this CBM well, water reserve, initial adsorbed gas reserve, initial free gas reserve, OGIP, and the permeability of the coal formation are evaluated, which are shown in Table 6. The fitting results from methods 1, 2, 3, and 5 are very close to each other, while the fitting results from method 4 is not good; so the evaluated results by method 4 is not used, but those evaluated by methods $1,2,3$, and 5 are used as the final results. Thus, the control radius of this CBM well is about $120 \mathrm{~m}$, the OGIP controlled by this CBM well is estimated to be about $540 \times 10^{4} \mathrm{~m}^{3}$, which is in accordance with OGIP evaluated by Shi's MBE method (Shi et al. 2018a). The permeability of the coal formation is evaluated to be about $0.22 \mathrm{mD}$, which agrees with the evaluated permeability for Muai research area by Shi's method using dewatering data (Shi et al. 2018b, 2019a).

\section{Discussion}

(1) Free gas may exist in undersaturated CBM reservoirs

Based on the current classification of CBM reservoirs, CBM reservoirs are classified as saturated and undersaturated according to the difference between the measured and theoretical gas contents (Zhao et al. 2014). Although the measured total gas amount is less than the theoretical adsorption gas content estimated by the Langmuir equation at the initial reservoir pressure, few evidences indicate that all the measured gas amounts are in adsorbed state. In reality, the existence of free gas in undersaturated CBM reservoirs has already been proven through field applications (Sun et al. 2017, 2018b; Shi et al. 2018a, 2019b), such as the Muai CBM reservoir in the Junlian production area in the southern Sichuan Basin, the initial water saturation is fitted to be less than 1 during the history matching process, demonstrating there is a small amount of free gas in this undersaturated CBM reservoir. Furthermore, some researchers have concluded that there exist tight sandstone gas layers with free gas from nearby coal seams although these coal seams are measured and classified as undersaturated CBM reservoirs (Li et al. 2018), indicating that there must exist free gas in these undersaturated CBM reservoirs in the past and there may still exist some free gas at the current state.

The possible forming mechanism of such CBM reservoirs can be described as follows. When a saturated CBM reservoir (which contains excessive methane) subsides to a deeper formation because of tectonic movement, the pressure increases rapidly, but the methane generation is very gradual, resulting in that the actual adsorption gas amount is less than the expected adsorption gas amount after subsidence. In this case, the actual adsorption gas amount in 
this CBM reservoir is equal to the expected adsorption gas amount at the formation pressure before subsidence, and the free gas in this saturated CBM reservoir before subsidence cannot re-adsorb to the coal surface to become adsorption gas again because of water existence in coal formation; this CBM reservoir will be called undersaturated CBM reservoir with some free gas.

(2) The application condition and effectiveness of the proposed five FMBE methods

As mentioned above in the field case study, the FMBE method 4 is not applicable when the water production rate approximately remains constant, but it is effective for the case that the daily water production is continuously changing. Different from the method 4, the other four FMBE methods are constantly suitable no matter whether the water production rate is stable or not. The FMBE method 1 is more applicable for the case with relatively high water production rate. On the contrary, method 2 is more accurate for CBM wells with low water production rate. As for method 3 , since it focuses more on the early dewatering stage, it has more accuracy than other methods for the case with large variation of water production at the late dewatering stage. The FMBE method 5 is the most stable method with almost the highest $R^{2}$ in fitting plot. It is worth noting that from derivation processes of these five methods, only in method 4 the water influx $W_{\mathrm{e}}$ is not assumed to be 0 , demonstrating that method 4 is still applicable for undersaturated CBM reservoirs with water influx. In other words, method 4 enjoys higher priority compared to the other four methods for the case without information about water influx.

In field application, these five FMBE methods can be used together to evaluate the control area of the CBM well, the water reserve, the initial water reserve, the initial adsorbed gas reserve, the initial free gas reserve, OGIP, and the permeability of the coal formation. The most rational values can be determined from the final results via comparing and analyzing these fitting results evaluated by these five methods.

\section{Summary and conclusions}

1. On the basis of water productivity equation of a CBM well and the MBE for undersaturated CBM reservoirs at the dewatering stage, the FMBE is established for undersaturated CBM reservoirs, which considers immobile free gas expansion effect; then five straight-line methods are proposed to determine the control area, initial water reserve, initial free gas reserve, initial adsorbed gas reserve, OGIP, and permeability at the same time. Two validation cases with and without considering free gas expansion prove the effectiveness of the proposed five FMBE methods.

2. Only the bottom-hole pressure and water production rate data during the time range after the pseudo-steady state and before gas desorption are needed for evaluating the water and gas reserves controlled by the CBM well and the permeability of coal formation simultaneously using the proposed five FMBE methods. These five methods should be broadly applied in field cases.

3. The immobile free gas expansion should be considered in the total compressibility expression when establishing the MBE of undersaturated CBM reservoirs at the dewatering stage. A small amount of free gas will result in a large increase in the total compressibility. If the free gas expansion effect is ignored, the control area of the CBM well, water reserve and OGIP will be greatly overestimated.

Acknowledgements The research was supported by the National Science and Technology Major Projects of China (No. 2016ZX05042 and No. 2017ZX05039) and the National Natural Science Foundation Projects of China (No. 51504269 and No. 51490654). The authors acknowledge Science Foundation of China University of Petroleum, Beijing (No.C201605) to support part of this work.

Open Access This article is licensed under a Creative Commons Attribution 4.0 International License, which permits use, sharing, adaptation, distribution and reproduction in any medium or format, as long as you give appropriate credit to the original author(s) and the source, provide a link to the Creative Commons licence, and indicate if changes were made. The images or other third party material in this article are included in the article's Creative Commons licence, unless indicated otherwise in a credit line to the material. If material is not included in the article's Creative Commons licence and your intended use is not permitted by statutory regulation or exceeds the permitted use, you will need to obtain permission directly from the copyright holder. To view a copy of this licence, visit http://creativecommons.org/licenses/by/4.0/.

\section{References}

Adeboye OO, Bustin RM. Variation of gas flow properties in coal with probe gas, composition and fabric: examples from western Canadian sedimentary basin. Int J Coal Geol. 2013;108:47-52. https ://doi.org/10.1016/j.coal.2011.06.015.

Ahmed TH, Centilmen A, Roux BP. A generalized material balance equation for coalbed methane reservoirs. In: SPE annual technical conference and exhibition, 24-27 September, San Antonio; 2006. https://doi.org/10.2118/102638-MS.

Al-Khalifa AA, Horne RN, Azia K. In-place determination of reservoir relative permeability using well test analysis. In: Middle East Oil Show, 11-14 March, Bahrain; 1989. https://doi. org/10.2118/17973-MS.

Aminian K, Ameri S, Bhavsar A, Sanchez M, Garcia A. Type curves for coalbed methane production prediction. In: SPE eastern regional meeting, 15-17 September, Charleston, West Virginia; 2004. https://doi.org/10.2118/91482-MS.

Cheng L. Mechanics of fluids in porous media. Beijing: Petroleum Industry Press; 2011 (in Chinese). 
Clarkson CR. Case study: production data and pressure transient analysis of horseshoe canyon CBM wells. In: CIPC/SPE gas technology symposium 2008 joint conference, 16-19 June, Calgary, Alberta, Canada; 2008. https://doi.org/10.2118/114485-MS.

Clarkson CR. Production data analysis of unconventional gas wells: Review of theory and best practices. Int J Coal Geol. 2013;109110:101-46. https://doi.org/10.1016/j.coal.2013.01.002.

Clarkson CR, Jordan CL, Gierhart RR, Seidle JP. Production data analysis of CBM wells. In: Rocky mountain oil and gas technology symposium, 16-18 April, Denver; 2007. https://doi. org/10.2118/107705-MS.

Clarkson CR, Jordan CL, Gierhart RR, Seidle JP. Production data analysis of coalbed-methane wells. SPE Reserv Eval Eng. 2008;11(02):311-25. https://doi.org/10.2118/107705-PA.

Clarkson CR, Rahmanian M, Kantzas A, Morad K. Relative permeability of CBM reservoirs: controls on curve shape. Int J Coal Geol. 2011;88(4):204-17. https://doi.org/10.1016/j.coal.2011.10.003.

Clarkson CR, Jordan CL, Ilk D, Blasingame TA. Rate-transient analysis of 2-phase (gas + water) CBM wells. J Nat Gas Sci Eng. 2012;8:106-20. https://doi.org/10.1016/j.jngse.2012.01.006.

Clarkson CR, Salmachi A. Rate-transient analysis of an undersaturated CBM reservoir in Australia: accounting for effective permeability changes above and below desorption pressure. J Nat Gas Sci Eng. 2017;40:51-60. https://doi.org/10.1016/j.jngse.2017.01.030.

Conway MW, Mavor MJ, Saulsberry J, Barree RB, Schraufnagel RA. Multi-phase flow properties for coalbed methane wells: a laboratory and field study. In: Low permeability reservoirs symposium, 19-22 March, Denver; 1995. https://doi.org/10.2118/29576-MS.

Dejam M. Advective-diffusive-reactive solute transport due to nonNewtonian fluid flows in a fracture surrounded by a tight porous medium. Int J Heat Mass Transf. 2019;128:1307-21. https://doi. org/10.1016/j.ijheatmasstransfer.2018.09.061.

Dejam M, Hassanzadeh H, Chen Z. Shear dispersion in a fracture with porous walls. Adv Water Resour. 2014;74:14-25. https://doi. org/10.1016/j.advwatres.2014.08.005.

Dejam M, Hassanzadeh H, Chen Z. Pre-Darcy flow in porous media. Water Resour Res. 2017;53(10):8187-210. https://doi. org/10.1002/2017WR021257.

Dejam M, Hassanzadeh H, Chen Z. Semi-analytical solution for pressure transient analysis of a hydraulically fractured vertical well in a bounded dual-porosity reservoir. J Hydrol. 2018a;565:289-301. https://doi.org/10.1016/j.jhydrol.2018.08.020.

Dejam M, Hassanzadeh H, Chen Z. Shear dispersion in a roughwalled fracture. SPE Journal. 2018b;23(5):1669-88. https://doi. org/10.2118/189994-PA.

Fu X, Qin Y, Wang GGX, Rudolph V. Evaluation of coal structure and permeability with the aid of geophysical logging technology. Fuel. 2009;88(11):2278-85. https://doi.org/10.1016/j.fuel.2009.05.018.

Gash BW. Measurement of "Rock Properties" in coal for coalbed methane production. In: SPE annual technical conference and exhibition, 6-9 October, Dallas; 1991. https://doi.org/10.2118/22909 -MS.

Gerami S, Pooladi-Darvish M, Morad K, Mattar L. Type curves for dry CBM reservoirs with equilibrium desorption. In: Canadian international petroleum conference, 12-14 June, Calgary; 2007. https://doi.org/10.2118/08-07-48.

Guzman JD, Arevalo JA, Espinola O. Reserves evaluation of dry gas reservoirs through flowing pressure material balance method. In: SPE energy resources conference, 9-11 June, Port of Spain; 2014. https://doi.org/10.2118/169989-MS.

Ibrahim MH, Wattenbarger RA. Analysis of rate dependence in transient linear flow in tight gas wells. In: Abu Dhabi international petroleum exhibition and conference, 5-8 November, Abu Dhabi; 2006. https://doi.org/10.2118/100836-MS.

Jenkins CD, Boyer CM. Coalbed-and shale-gas reservoirs. J Pet Technol. 2008;60(2):92-9. https://doi.org/10.2118/103514-JPT.
Karacan CÖ. Reservoir rock properties of coal measure strata of the Lower Monongahela Group, Greene County (Southwestern Pennsylvania), from methane control and production perspectives. Int J Coal Geol. 2009;78(1):47-64. https://doi.org/10.1016/j. coal.2008.10.005

King GR. Material balance techniques for coal seam and Devonian shale gas reservoirs. In: SPE annual technical conference and exhibition, 23-26 September, New Orleans; 1990. https://doi. org/10.2118/20730-MS.

King GR. Material-balance techniques for coal-seam and Devonian shale gas reservoirs with limited water influx. SPE Reserv Eng. 1993;8(01):67-72. https://doi.org/10.2118/20730-PA.

Li S. Gas engineering. Beijing: Petroleum Industry Press; 2008 (in Chinese).

Li J, Liu D, Yao Y, Cai Y, Qiu Y. Evaluation of the reservoir permeability of anthracite coals by geophysical logging data. Int J Coal Geol. 2011;87(2):121-7. https://doi.org/10.1016/j. coal.2011.06.001.

Li Y, Tang D, Xu H, Meng Y, Li J. Experimental research on coal permeability: the roles of effective stress and gas slippage. J Nat Gas Sci Eng. 2014;21:481-8. https://doi.org/10.1016/j.jngse .2014.09.004

Li J, Tang S, Zhang S, Li L, Wei J, Xi Z, et al. Characterization of unconventional reservoirs and continuous accumulations of natural gas in the Carboniferous-Permian strata, mid-eastern Qinshui basin, China. J Nat Gas Sci Eng. 2018;49:298-316. https://doi. org/10.1016/j.jngse.2017.10.019.

Liu S, Harpalani S. Permeability prediction of coalbed methane reservoirs during primary depletion. Int J Coal Geol. 2013;113:1-10. https://doi.org/10.1016/j.coal.2013.03.010.

Mattar L, Anderson D, Stotts GG. Dynamic material balance-oil-or gas-in-place without Shut-Ins. J Can Pet Technol. 2006;45(11):710. https://doi.org/10.2118/06-11-TN.

McNeil R. The "flowing" material balance procedure. In: Annual technical meeting, 7-9 June, Calgary; 1995. https://doi. org/10.2118/95-77.

Morad K, Clarkson CR. Application of flowing p/Z* material balance for dry coalbed-methane reservoirs. In: CIPC/SPE gas technology symposium 2008 joint conference, 16-19 June, Calgary; 2008. https://doi.org/10.2118/114995-MS.

Salmachi A, Karacan CÖ. Cross-formational flow of water into coalbed methane reservoirs: controls on relative permeability curve shape and production profile. Environ Earth Sci. 2017;76(5):200. https ://doi.org/10.1007/s12665-017-6505-0.

Salmachi A, Dunlop E, Rajabi M, Yarmohammadtooski Z, Begg S. Investigation of permeability change in ultra-deep coal seams using time-lapse pressure transient analysis: a pilot project in the Cooper Basin, South Australia. AAPG Bull. 2019;103(1):91-107. https://doi.org/10.1306/05111817277.

Saulsberry JL, Schafer PS, Schraufnagel RA. A guide to coalbed methane reservoir engineering. In: Gas research institute. Report GRI94/0397, Chicago; 1996.

Shi J, Chang Y, Wu S, Xiong X, Liu C, Feng K. Development of material balance equations for coalbed methane reservoirs considering dewatering process, gas solubility, pore compressibility and matrix shrinkage. Int J Coal Geol. 2018a;195:200-16. https://doi. org/10.1016/j.coal.2018.06.010.

Shi J, Wang S, Zhang H, Sun Z, Hou C, Chang Y, et al. A novel method for formation evaluation of undersaturated coalbed methane reservoirs using dewatering data. Fuel. 2018b;229:44-52. https://doi. org/10.1016/j.fuel.2018.04.144.

Shi J, Wang S, Xu X, Sun Z, Li J, Meng Y. A semi-analytical productivity model for a vertically fractured well with arbitrary fracture length under complex boundary conditions. SPE Journal. 2018c;23(06):2080-102. https://doi.org/10.2118/191368-PA. 
Shi J, Wang S, Wang K, Liu C, Wu S, Sepehrnoori K. An accurate method for permeability evaluation of undersaturated coalbed methane reservoirs using early dewatering data. Int J Coal Geol. 2019a;202:147-60. https://doi.org/10.1016/j.coal.2018.12.008.

Shi J, Hou C, Wang S, Xiong X, Wu S, Liu C. The semi-analytical productivity equations for vertically fractured coalbed methane wells considering pressure propagation process, variable mass flow, and fracture conductivity decrease. J Pet Sci Eng. 2019b;178:528-43. https://doi.org/10.1016/j.petrol.2019.03.047.

Sun Z, Li X, Shi J, Yu P, Huang L, Xia J, et al. A semi-analytical model for drainage and desorption area expansion during coal-bed methane production. Fuel. 2017;204:214-26. https://doi.org/10.1016/j. fuel.2017.05.047.

Sun Z, Li X, Shi J, Zhang T, Feng D, Sun F, et al. A semi-analytical model for the relationship between pressure and saturation in the CBM reservoirs. J Nat Gas Sci Eng. 2018a;49:365-75. https://doi. org/10.1016/j.jngse.2017.11.022.

Sun Z, Shi J, Wang K, Miao Y, Zhang T, Feng D, et al. The gas-water two phase flow behavior in low-permeability CBM reservoirs with multiple mechanisms coupling. J Nat Gas Sci Eng. 2018b;52:82 93. https://doi.org/10.1016/j.jngse.2018.01.027.

Sun Z, Shi J, Zhang T, Zhang T, Wu K, Miao Y, et al. The modified gas-water two phase version flowing material balance equation for low permeability CBM reservoirs. J Pet Sci Eng. 2018c;165:72635. https://doi.org/10.1016/j.petrol.2018.03.011.

Sun Z, Shi J, Zhang T, Wu K, Feng D, Sun F, et al. A fully-coupled semi-analytical model for effective gas/water phase permeability during coal-bed methane production. Fuel. 2018d;223:44-52. https://doi.org/10.1016/j.fuel.2018.03.012.

Wang S, Elsworth D, Liu J. Permeability evolution in fractured coal: the roles of fracture geometry and water-content. Int J Coal Geol. 2011;87(1):13-25. https://doi.org/10.1016/j.coal.2011.04.009.
Yan T, Yao Y, Liu D, Bai Y. Evaluation of the coal reservoir permeability using well logging data and its application in the Weibei coalbed methane field, southeast Ordos basin, China. Arab J Geosci. 2015;8(8):5449-58. https://doi.org/10.1007/s12517-014-1661-y.

Yarmohammadtooski Z, Salmachi A, White A, Rajabi M. Fluid flow characteristics of Bandanna Coal Formation: a case study from the Fairview Field, eastern Australia. Aust J Earth Sci. 2017;64(3):319-333. https://doi.org/10.1080/08120 099.2017.1292316.

Zahner B. Application of material balance to determine ultimate recovery of a San Juan Fruitland coal well. In: SPE annual technical conference and exhibition, 5-8 October, San Antonio; 1997. https ://doi.org/10.2118/38858-MS.

Zhang L, Kou Z, Wang H, Zhao Y, Dejam M, Guo J, et al. Performance analysis for a model of a multi-wing hydraulically fractured vertical well in a coalbed methane gas reservoir. J Pet Sci Eng. 2018;166:104-20. https://doi.org/10.1016/j.petrol.2018.03.038.

Zhao J, Tang D, Xu H, Meng Y, Lv Y, Tao S. A dynamic prediction model for gas-water effective permeability in unsaturated coalbed methane reservoirs based on production data. J Nat Gas Sci Eng. 2014;21:496-506. https://doi.org/10.1016/j.jngse.2014.09.014.

Zhou F, Guan Z. Uncertainty in estimation of coalbed methane resources by geological modelling. J Nat Gas Sci Eng. 2016;33:988-1001. https://doi.org/10.1016/j.jngse.2016.04.017.

Zhu S, Salmachi A, Du Z. Two phase rate-transient analysis of a hydraulically fractured coal seam gas well: a case study from the ordos basin, China. Int J Coal Geol. 2018;195:47-60. https://doi. org/10.1016/j.coal.2018.05.014. 